\title{
Graphene-PSS/L-DOPA nanocomposite cation exchange membranes for electrodialysis desalination
}

DOI:

10.1039/D0ENO0496K

Document Version

Accepted author manuscript

Link to publication record in Manchester Research Explorer

\section{Citation for published version (APA):}

Alabi, A., Cseri, L., Alhajaj, A., Szekely, G., Budd, P. M., \& Zou, L. (2020). Graphene-PSS/L-DOPA nanocomposite cation exchange membranes for electrodialysis desalination. Environmental Science: Nano. https://doi.org/10.1039/D0EN00496K

\section{Published in:}

Environmental Science: Nano

\section{Citing this paper}

Please note that where the full-text provided on Manchester Research Explorer is the Author Accepted Manuscript or Proof version this may differ from the final Published version. If citing, it is advised that you check and use the publisher's definitive version.

\section{General rights}

Copyright and moral rights for the publications made accessible in the Research Explorer are retained by the authors and/or other copyright owners and it is a condition of accessing publications that users recognise and abide by the legal requirements associated with these rights.

\section{Takedown policy}

If you believe that this document breaches copyright please refer to the University of Manchester's Takedown Procedures [http://man.ac.uk/04Y6Bo] or contact uml.scholarlycommunications@manchester.ac.uk providing relevant details, so we can investigate your claim.

\section{OPEN ACCESS}




\section{Graphene-PSS/L-DOPA nanocomposite mixed matrix cation exchange}

\section{2 membranes for electrodialysis desalination}

3 Adetunji Alabi ${ }^{1}$, Levente Cseri $^{2}$, Ahmed Al Hajaj ${ }^{3}$, Gyorgy Szekely ${ }^{2,4}$, Peter Budd ${ }^{5}$, Linda $4 \mathrm{Zou}^{1 *}$

$5{ }^{1}$ Department of Civil Infrastructure and Environmental Engineering, Khalifa University of 6 Science and Technology, PO Box 127788, Abu Dhabi, United Arab Emirates

$7 \quad{ }^{2}$ Department of Chemical Engineering and Analytical Science, University of Manchester, The 8 Mill, Sackville Street, Manchester, M1 3BB, United Kingdom

$9{ }^{3}$ Department of Chemical Engineering, Khalifa University of Science and Technology, PO Box 10 127788, Abu Dhabi, United Arab Emirates

$11{ }^{4}$ Advanced Membranes \& Porous Materials Center, Physical Science Engineering Division 12 (PSE), King Abdullah University of Science and Technology (KAUST), Thuwal 23955-6900, 13 Saudi Arabia

$14{ }^{5}$ Department of Chemistry, University of Manchester, Oxford Road, Manchester, M13 9PL, 15 United Kingdom

*Corresponding author

17 Email: linda.zou@ku.ac.ae 


\section{Abstract}

21 This research reports the fabrication of nanocomposite cation exchange membranes (CEMs) by incorporating negatively charged graphene-based nanomaterials into a non-charged poly(vinylidene fluoride) (PVDF) matrix using a mold-casting technique developed in-house. Graphene oxide (GO) or reduced graphene oxide (rGO) nanosheets were modified into ion exchange group carriers using a sulfonic group-bearing agent based on poly(sodium 4styrenesulfonate)/3,4-dihydroxy-L-phenylalanine (PSS/L-DOPA) (SGO or SrGO). Such modified nanosheets provide the ion exchange capabilities in SGO/PVDF and SrGO/PVDF nanocomposite CEMs, respectively. Both nanocomposite CEMs displayed lower linear swelling ratios which are good for membrane stability. This was due to the presence of the nanomaterials which acted as pore fillers and increased the stiffness of the nanocomposite membranes. The ion exchange capacity (IEC) and permselectivity of the SGO/PVDF_45 CEMs were slightly higher than the values for the SrGO/PVDF_45 CEM. It was found that the SrGO additive increased the area resistance of the nanocomposite CEM. However, SrGO/PVDF_45 CEM demonstrated a higher current efficiency $(7.5 \%$ higher than SGO/PVDF_45), which could be attributed to the improved electronic conductivity of rGO. It was found that both nanocomposite CEMs performed well in electrodialysis experiments to achieve the substantial salt removal rates, although the energy consumption results of the novel nanocomposite CEMs were higher than the conventional polymeric CEM. The above research results have successfully demonstrated the concept of fabricating nanocomposite cation exchange membranes (CEMs) for electrodialysis applications by employing negatively 41 charged graphene-based nanomaterials as ion exchange carriers.

Keywords: Graphene oxide, reduced graphene oxide, nanocomposite ion exchange membranes, 44 electrodialysis desalination 


\section{Introduction}

46 Ion exchange membranes (IEMs) have received great attention from the research and industrial

47 communities due to their role in electromembrane processes, which range from energy

48 production to desalination. Given the rapid increase in demand for fresh water, technologies

49 such as electromembrane desalination processes have been used to meet the fresh water needs

50 of society. Electromembrane desalination processes, which include electrodialysis (ED) $)^{1-7}$ and

51 membrane capacitive deionization (MCDI), ${ }^{8-12}$ use the electrochemical potential difference in

52 an ionic solution as the driving force for ionic transport through IEMs. IEMs are then able to carry out salt removal by preferentially allowing the flow of oppositely charged ions through them, while preventing the passage of similarly charged ions.

The development of IEMs with desirable electrochemical and physico-chemical properties for efficient fresh water production is therefore important. Numerous strategies have been investigated to prepare IEMs with superior properties for enhanced electromembrane desalination performance. These strategies include: ${ }^{13-15}$ variation of charged functional groups on the polymer backbone of the IEM, modification of the IEM's surface, combination of different polymers to take advantage of their desirable properties, inclusion of chemical additives, and cross-linking to improve mechanical stability. Another emerging approach for improving the properties of IEMs is the incorporation of nanomaterials into polymeric matrices of IEMs to produce nanocomposite IEMs. ${ }^{16-18}$ However, until recently, it was found in the nanocomposite IEMs literature that nanomaterials have been used only as a minor additive (nanomaterial content varied between 0.5 - 15 wt.\% of the IEMs) to improve the IEMs' physical properties, whereas the ion exchange capabilities were derived primarily from charged polymeric materials. ${ }^{16,19-21}$ Since nanomaterials can be functionalized with charged groups and also serve as ion conducting channels, the use of nanomaterials to provide ion exchange properties should be investigated. This had not been reported until we successfully 
demonstrated the concept in our recent work where a nanocomposite cation exchange membrane (CEM) was prepared based on modified graphene oxide (SGO) nanosheets and inert polyvinylidene (PVDF). ${ }^{22}$ Having demonstrated a proof of concept, the possibility of using reduced GO has not been investigated yet; particularly the exploration of the implications of the difference in nanostructure of chemically reduced graphene oxide nanosheets, such as partial removal of oxygen containing groups and reduction of interlayer spaces, on the CEM properties and performance.

Properties that make graphene-based nanosheets suitable for nanocomposite ion exchange membranes include: (1) they are 2D nanosheets with high surface area; (2) they have high dispersibility in many organic solvents used for preparing casting solutions; (3) they have high mechanical and thermal stability; and (4) they form ion conducting channels for ionic transport

81 facilitation. ${ }^{16,23,24}$

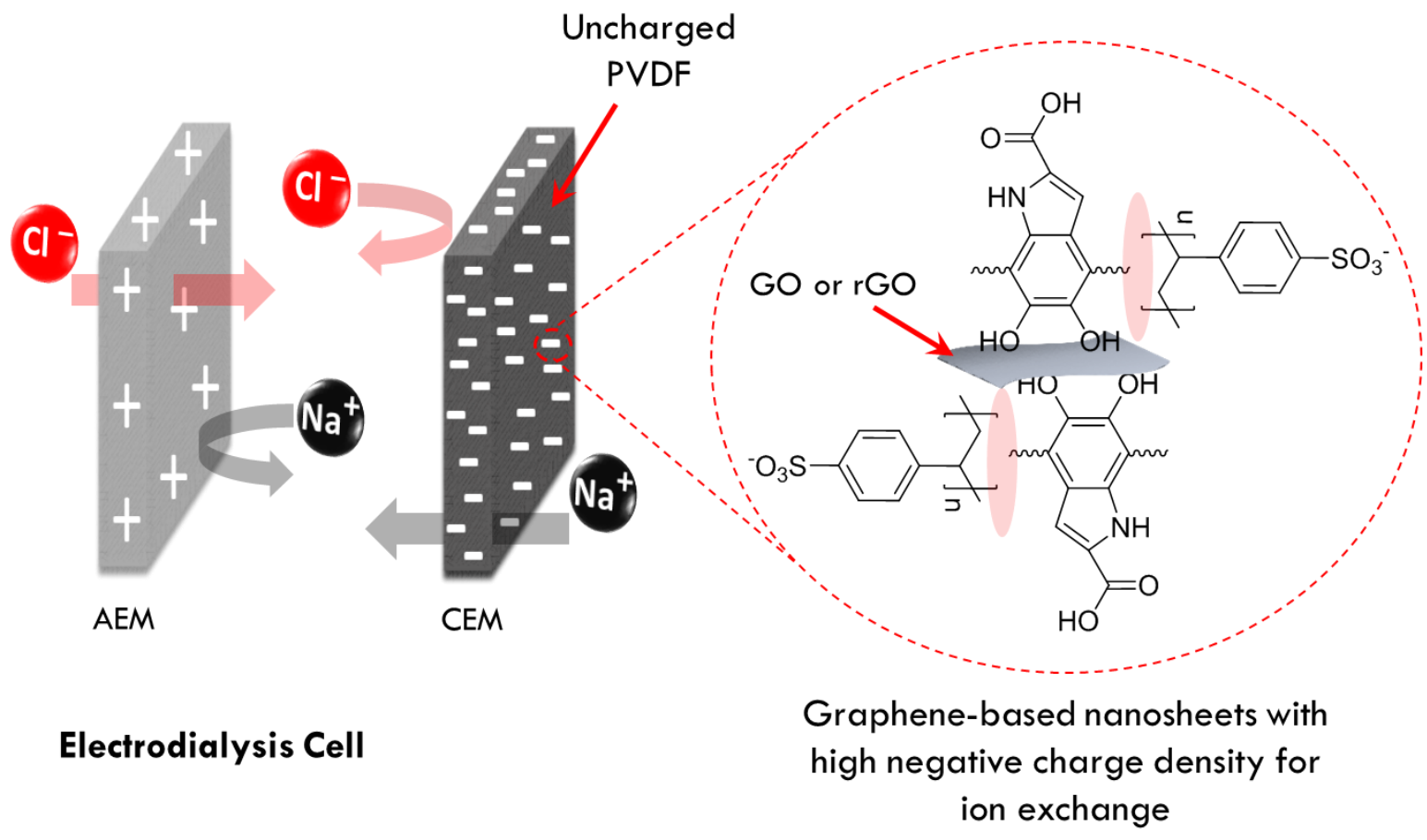

Figure 1 Electrodialysis cell and components of the fabricated nanocomposite CEMs. 
83 L-DOPA has catechol groups which possess strong adhesion to many surfaces. ${ }^{25}$ PSS has a

84 high content of sulfonic-acid groups for ion exchange. By electrostatically coupling PSS and L-DOPA together, a sulfonic-group incorporating agent is produced which is able to form noncovlent bonds with the surfaces of the graphene-based nanosheets. Strong adhesive capabilities are observed for molecules with a high concentration of 3,4-dihydroxyphenylalanine (LDOPA). L-DOPA is an amino acid which marine mussels secrete for strong adhesion to wet surfaces. ${ }^{25}$ L-DOPA forms strong covalent and non-covalent bonds with the surface of numerous types of materials ${ }^{26}$ including $\mathrm{PSS}^{27}$ and graphene oxide. ${ }^{28}$ The formation of polydopamine involves the polymerization of dopamine via auto-oxidation to form dopaminequinone and 5,6-dihydroxiyindole. ${ }^{29}$ Similarly to the dopamine, L-DOPA self-polymerizes to form poly(L-DOPA) ${ }^{30}$. The poly(L-DOPA) can attach to PSS by physical co-adsorption to produce an adsorbed layer [ref]. While the catechol groups, from poly(L-DOPA), enable the adhesion of the sulfonic-group incorporating agent to the graphene-based nanosheets. ${ }^{28}$

GO was evaluated in our previous research work for improving the properties of IEMs. Zheng et al. demonstrated the incorporation of chemically reduced $\mathrm{GO}(\mathrm{rGO})$ into polymeric matrices for the purpose of reducing membrane swelling. ${ }^{31}$ Since rGO has less oxygen containing functional groups, it is expected to produce membranes with less swelling (and consequently 100 more stability), and possibly higher electronic conductivity. By reducing GO, improvement may be achieved in both memebrane structure and electronic properties. Furthermore, the impact of the reduction in the interlayer space of rGO can also influence the fabricated nanocomposite CEMs.

In this research, we investigate the effects of using as-prepared GO and chemically-reduced rGO to prepare ion exchange nanocomposites and incorporate them in inert PVDF polymer, and to assess the electrodialysis performance of the resultant nanocomposite CEMs. PVDF was

107 selected as the polymeric membrane material because of its chemical stability and robustness. 5 | P a g e 
108 It has been extensively used in membrane fabrication, and its membranes have demonstrated exceptional permeability, selectivity, and stability in water treatment applications. ${ }^{32,33}$

110 Reduced graphene oxide (rGO) or graphene oxide (GO) were modified using PSS/L-DOPA

111 modifying agent to produce SrGO- and SGO-based CEMs (Figure 1). Different weights of the

112 SrGO were incorporated into a fixed amount of PVDF to yield SrGO/PVDF with varying SrGO

113 loadings. The higher loading of the $\mathrm{SrGO}$ in the polymer matrix will lead to an increase of the

114 ion exchange capacity of the fabricated nanocomposite CEMs. The effect of the various

115 loadings was investigated. SGO/PVDF CEM and plain PVDF membranes were also prepared

116 for comparison of membrane structure and elecrochemical properties. Most importantly,

117 electrodialysis assessments were conducted on the nanocomposite CEMs to evaluate their

118 suitability for electromembrane desalination processes.

\section{Materials and Methods}

\section{$120 \quad 2.1 \quad$ Materials}

121 Graphite flakes were bought from Bay Carbon Inc. (USA).

122 Tris(hydroxymethyl)aminomethane, potassium permanganate $\left(\mathrm{KMnO}_{4}\right)$, sodium nitrite $123\left(\mathrm{NaNO}_{2}\right)$, hydrogen peroxide $\left(\mathrm{H}_{2} \mathrm{O}_{2}\right)$, hydrochloric acid $(\mathrm{HCl})$, potassium chloride $(\mathrm{KCl})$, 124 poly(vinylidene fluoride) (PVDF), sodium sulfate $\left(\mathrm{Na}_{2} \mathrm{SO}_{4}\right)$, sodium hydroxide $(\mathrm{NaOH}), N$ 125 methyl-2-pyrrolidone (NMP), L-ascorbic acid, 3,4-dihydroxy-L-phenylalanine (L-DOPA), 126 sulfuric acid $\left(\mathrm{H}_{2} \mathrm{SO}_{4}\right)$, and poly(sodium 4-styrenesulfonate) (PSS; 30 wt.\% in $\mathrm{H}_{2} \mathrm{O}$ ) were 127 obtained from Sigma Aldrich. Ethanol was purchased from Honeywell (USA). DI water was 128 used throughout the experiments. 


\subsection{Preparation of GO and rGO}

130 Graphene oxide was prepared from graphite powder by the modified Hummers method. ${ }^{34} 240$

$131 \mathrm{~mL}$ of concentrated $\mathrm{H}_{2} \mathrm{SO}_{4}$ was cooled in an ice bath for 40-45 min. $2 \mathrm{~g}$ of graphite powder and $1 \mathrm{~g}$ of $\mathrm{NaNO}_{2}$ were added to the chilled concentrated $\mathrm{H}_{2} \mathrm{SO}_{4}$ and stirred for $15 \mathrm{~min} .12 \mathrm{~g}$ of $\mathrm{KMnO}_{4}$ was slowly added to the mixture. Then the solution was stirred for $45 \mathrm{~min}$. The solution was put into a water bath at $35^{\circ} \mathrm{C}$ and stirred for $2 \mathrm{~h}$. Then the solution was put in an ice bath, after which of $250 \mathrm{~mL}$ DI water was slowly added. Then the solution was stirred continuously at room temperature for $2 \mathrm{~h}$. Afterwards, $500 \mathrm{~mL}$ DI water was added to the solution. Then $\mathrm{H}_{2} \mathrm{O}_{2}$ was slowly added until the color of the solution became golden yellow. The solution was vacuum filtered to obtain graphite oxide cake. The mud was then washed twice with $400 \mathrm{~mL}$ dilute $\mathrm{HCl}$ solution (1:10 by volume). Then the mud was washed twice with $500 \mathrm{~mL}$ DI water. $500 \mathrm{~mL}$ DI water was added to the graphite oxide cake. This graphite oxide

141 dispersion $(8 \mathrm{~g} / \mathrm{L})$ was then exfoliated using a probe ultrasonicator to produce graphene oxide 142 (GO).

143 To prepare chemically reduced GO (rGO), GO was reduced by mixing with $0.1 \mathrm{~g}$ L-ascorbic 144 acid and stirring continuously for $24 \mathrm{~h}$ (Figure 3a). ${ }^{35} \mathrm{~L}$-ascorbic acid has been reported as a green and mild reducing agent used for reducing GO. ${ }^{36,37}$ The solution turned from brown to black in color. The reduction of GO to rGO was indicated by the change in coloration from brown to black. FTIR characterization confirmed the reduction.

\subsection{Preparation of PSS/L-DOPA-based sulfonic group-incorporating agent}

$1.5 \mathrm{~g}$ L-DOPA was added to $750 \mathrm{~mL}$ Tris- $\mathrm{HCl}$ buffer solution ( $\mathrm{pH}$ 8.4) and continuously stirred at room temperature for $1 \mathrm{~h}$. The L-DOPA dissolved and the solution turned from colorless to dark brown. This was followed by addition of $15 \mathrm{~mL}$ PSS and stirring at room temperature for

$15224 \mathrm{~h}$ to produce a PSS/L-DOPA modifying agent. A scheme is shown in Figure 2. This sulfonic- 
group incorporating solution was later used to modify GO and rGO. The sulfonic groups

154 provide negative charges for ion exchange. The catechol groups, which possess high adhesive 155 properties, are responsible for the coupling of the modifying agent to the GO and rGO 156 nanosheets.
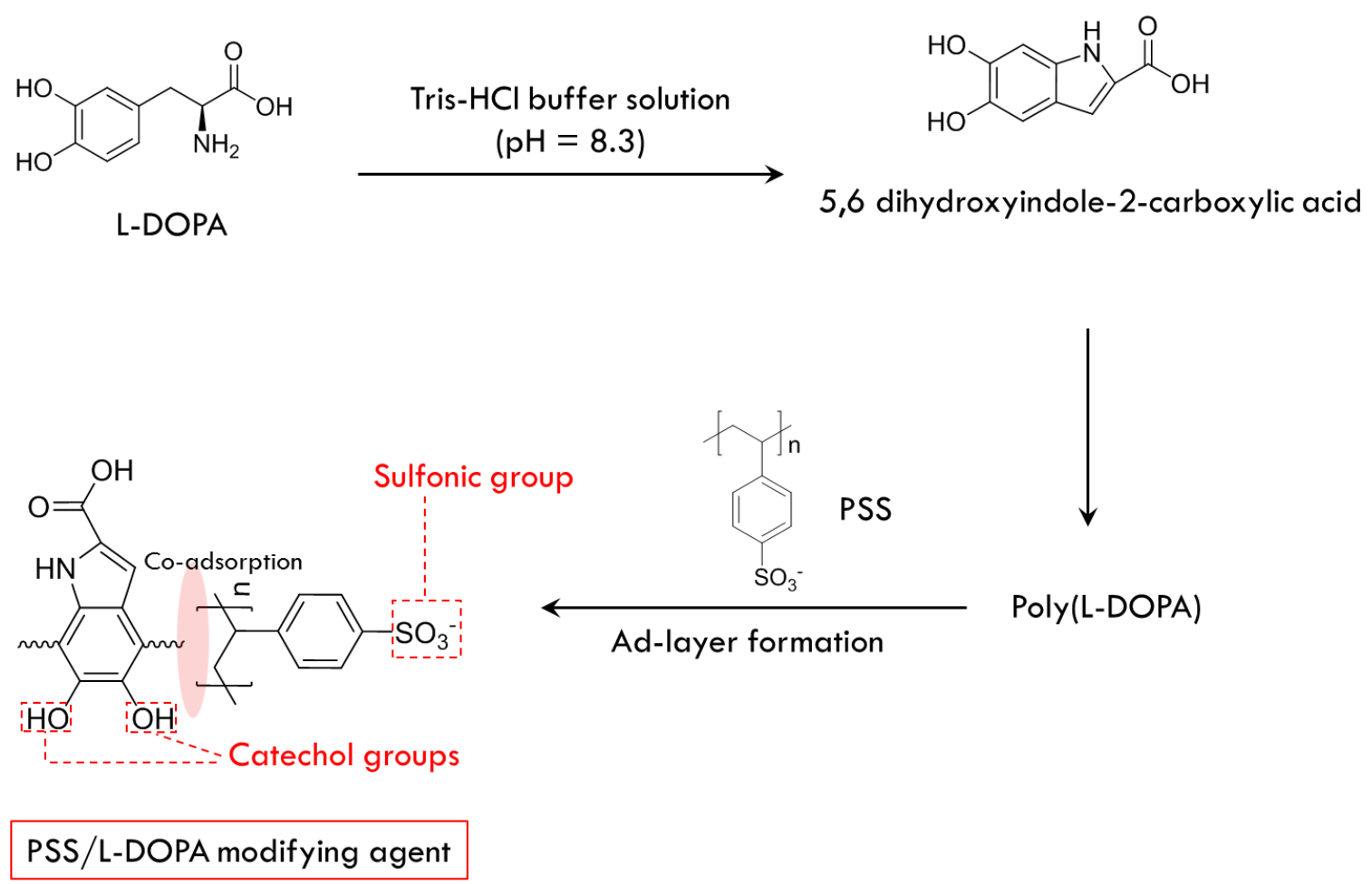

Figure 2 Scheme for the preparation of the PSS/L-DOPA sulfonic group incorporating agent.

\subsection{Modification of GO and rGO via electrostatically coupling with PSS/L-} DOPA

160 The incorporation of sulfonic groups on GO and rGO was achieved via mixing with PSS/L-

161 DOPA modifying agent (Figure 3b). $150 \mathrm{~mL} \mathrm{GO}$ dispersion was added to a beaker, and $150 \mathrm{~mL}$

162 rGO dispersion was added to a separate beaker. Then $750 \mathrm{~mL}$ sulfonic group incorporating 163 agent was added to each beaker and stirred at room temperature for $48 \mathrm{~h}$. Afterwards, the 164 solutions were centrifuged multiple times and washed with DI water several times. The 
167 SGO and SrGO dispersions were then freeze dried to obtain dry and spongy SGO and SrGO.

168 By using the obtained dry and spongy SGO or SrGO, a casting solution of uniform consistency

169 and dispersion could be easily achieved. Coagulation and aggregation of the casting solution

170 would be avoided, therefore ensuring the casting of good quality membranes.

a
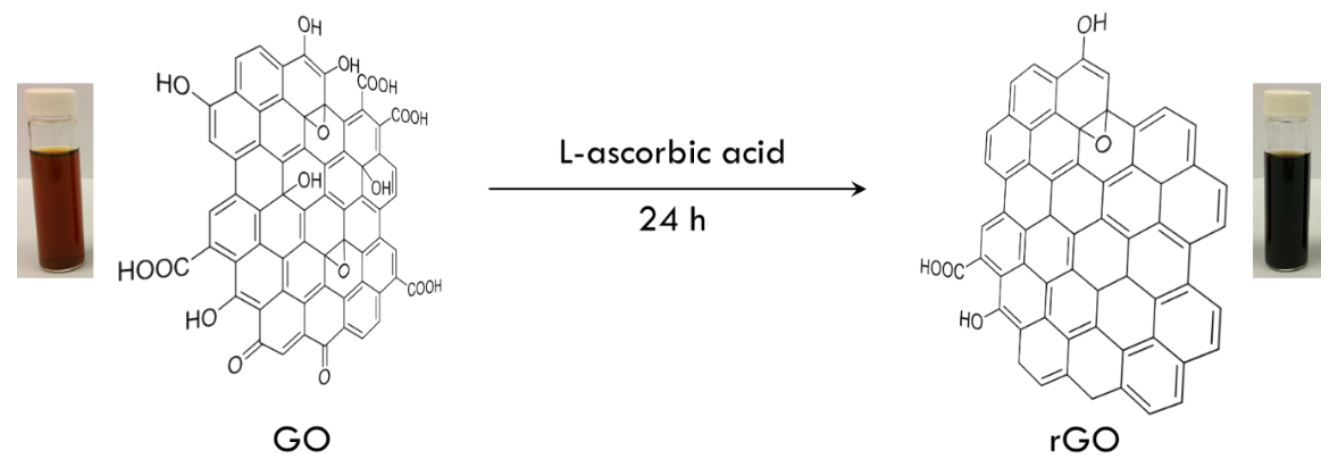

b

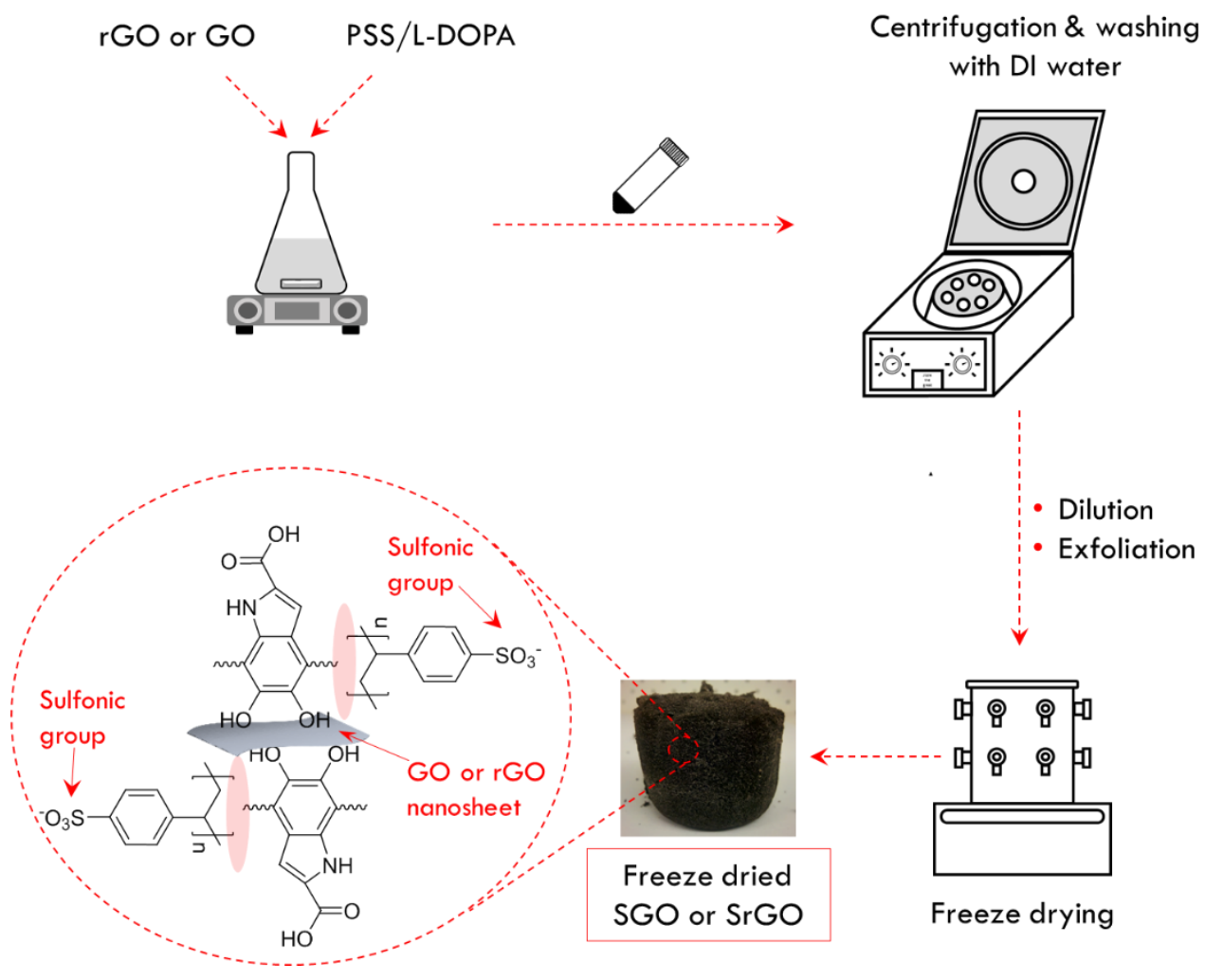

Figure 3 (a) Reduction of GO to rGO. (b) Preparation of PSS/L-DOPA modified GO (SGO) and PSS/L-DOPA modified rGO (SrGO). 


\subsection{Fabrication of Nanocomposite CEMs}

172 To fabricate the nanocomposite CEMs, casting solutions with compositions shown in Table 1

173 were first prepared. The membranes were then cast using the mold-casting method as

174 previously described. ${ }^{22}$ A schematic depiction of the fabrication process is shown in Figure 4.

Table 1 Composition of casting solutions used to fabricate the SGO/PVDF and SrGO/PVDF nanocomposite CEMs

\begin{tabular}{lrrrrr}
\hline Membrane & $\begin{array}{r}\text { PVDF } \\
(\mathrm{g})\end{array}$ & $\begin{array}{r}\text { SGO } \\
(\mathrm{g})\end{array}$ & $\begin{array}{r}\text { SrGO } \\
(\mathrm{g})\end{array}$ & $\begin{array}{r}\text { NMP } \\
(\mathrm{mL})\end{array}$ & $\begin{array}{r}\text { Nanomaterial loading, as } \\
\text { percentage of dry } \\
\text { membrane (wt.\%) }\end{array}$ \\
\hline SGO/PVDF_45 & 1.5 & 1.2 & - & 45 & 45 \\
SrGO/PVDF_45 & 1.5 & - & 1.2 & 45 & 45 \\
SrGO/PVDF_55 & 1.5 & - & 1.8 & 45 & 55 \\
SrGO/PVDF_65 & 1.5 & - & 2.8 & 45 & 65 \\
\hline
\end{tabular}

175

176 PVDF was added to NMP and heated at $55^{\circ} \mathrm{C}$ with continuous stirring for $4 \mathrm{~h}$. Then the heating

177 was stopped and the solution was stirred at room temperature. In separate beakers, SGO or SrGO was added to NMP and exfoliated in an ice bath for a total of $10 \mathrm{~min}$ at $1 \mathrm{~min}$ intervals.

Then the PVDF/NMP solution was mixed with the SGO/NMP or SrGO/NMP and stirred for

$18072 \mathrm{~h}$ to attain uniform mixing. The membrane thickness was controlled by ensuring a fixed amount of casting solution was used to cast each membrane sample. To achieve this, a syringe was used to administer $8 \mathrm{~mL}$ of the casting solution into the mold-casting setup. The moldcasting set-up comprised an aluminum square mold $(7 \times 7 \mathrm{~cm}$ internal dimension $)$ placed on

184 top of a silicon wafer. To prevent leakage of the casting solution, double clips were used to

185 fasten the mold-casting setup. Then the mold-casting setup was placed in an oven at $50{ }^{\circ} \mathrm{C}$ for 1864 days for temperature-induced phase inversion. The membrane samples were then placed in a water bath to peel off the membranes from the silicon wafer. 
188 To illustrate the effects of SrGO or SGO on the membrane morphology and structure, plain

189 PVDF membranes were also prepared using the same procedure as described above, but

190 without the addition of SGO or SrGO nanosheets to the polymeric matrix.

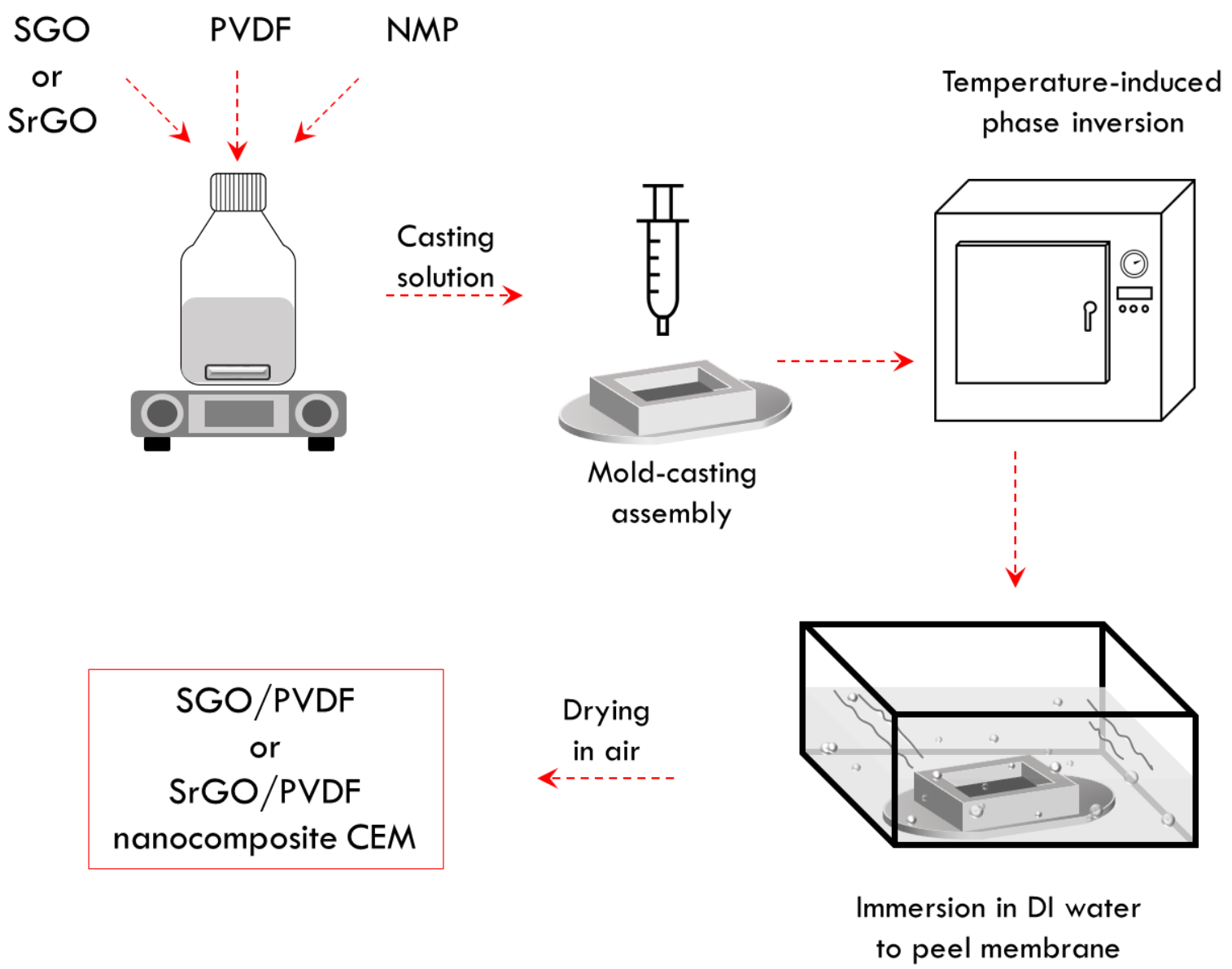

Figure 4 Fabrication of SGO/PVDF and SrGO/PVDF nanocomposite CEMs using the mold191 casting method.

\subsection{Characterization of Prepared Nanomaterials and Nanocomposite CEMs}

193 Raman spectroscopy was carried out with a Witec Alpha 300 RAS. An excitation wavelength 194 of $532 \mathrm{~nm}$ was used for all Raman characterizations. Fourier-Transform Infrared (FTIR) 195 spectroscopy was carried out using the Attenuated Total Reflectance (ATR) accessory of a 196 Bruker Vertex 80v FTIR spectrometer in transmittance mode. Scanning electron microscopy 
197 (SEM) images were obtained using a FEI ${ }^{\mathrm{TM}}$ Nova NanoSEM 650. The membrane samples were 198 coated with gold/palladium (Au/Pd) prior to imaging analyses. Elemental analyses and 199 mapping were done by energy-dispersive X-ray spectroscopy (EDS). The equipment used for 200 the EDS analyses was FEI Quanta 3D FEG, and the software used was TEAM ${ }^{\mathrm{TM}}$ EDS.

201 To carry out linear swelling ratio and water uptake measurements, the dry membrane samples 202 (of known weights and lengths) were first soaked in DI water for $24 \mathrm{~h}$. Then their new lengths 203 and weights were measured. The linear swelling ratio ${ }^{38,39}$ and water uptake were calculated 204 according to Equations (1) and (2), respectively.

$$
\text { Linear swelling ratio }=\frac{L_{\mathrm{w}}-L_{\mathrm{d}}}{L_{\mathrm{d}}} \times 100 \%
$$

205 where $L_{\mathrm{w}}$ is the length of the wet membrane and $L_{\mathrm{d}}$ is the length of the dry membrane.

$$
\text { Water uptake }=\frac{m_{\mathrm{w}}-m_{\mathrm{d}}}{m_{\mathrm{d}}} \times 100 \%
$$

206 where $m_{\mathrm{w}}$ is the mass of the wet membrane and $m_{\mathrm{d}}$ is the mass of the dry membrane.

207 Water contact angle measurements were taken using a Kyowa Dropmaster water contact angle goniometer, model DM-501. The software for analysis was FAMAS. For each membrane sample, 12 measurements were taken and the average was used as the final value.

210 Ion exchange capacity (IEC) was determined by the traditional acid-base titration technique. ${ }^{22,}$

$211{ }^{40}$ Briefly, membranes were converted to $\mathrm{H}^{+}$form by soaking in $50 \mathrm{~mL} 1 \mathrm{M} \mathrm{HCl}$ for $24 \mathrm{~h}$. The

212 weights of the membranes were measured prior to soaking. Afterwards, the membranes were 213 washed several times with DI water to rinse off excess $\mathrm{HCl}$ (To confirm that there was no more $214 \mathrm{HCl}$ present, $\mathrm{AgNO}_{3}$ was added to the wash water and carefully observed for the absence of 215 white precipitates). Then the membranes were transformed into the $\mathrm{Na}^{+}$form by immersing in $21650 \mathrm{~mL} 1 \mathrm{M} \mathrm{NaCl}$ for $24 \mathrm{~h}$. In this step, $\mathrm{H}^{+}$ions were displaced into the solution. The membrane12|P a g e 
soaked solution was then titrated against $0.01 \mathrm{M} \mathrm{NaOH}$ to evaluate the concentration of $\mathrm{H}^{+}$

218 ions within the solution. The IEC was calculated using Equation (3).

$$
\mathrm{IEC}=\frac{V_{\mathrm{NaOH}} C_{\mathrm{NaOH}}}{m_{\mathrm{dry}}}
$$

219 where $V_{\mathrm{NaOH}}$ is the volume of $\mathrm{NaOH}$ solution used in the titration, $C_{\mathrm{NaOH}}$ is the molar concentration of the $\mathrm{NaOH}$ consumed during the titration, and $m_{\text {dry }}$ is the mass of the dry membrane.

The permselectivity can be defined as an IEM's ability to preferentially allow oppositely charged ions to pass through. It is a measure of the fraction of oppositely charged ions (in relation to the total amount of ions) that pass through an IEM under an electrical potential difference. In an ideal case, an IEM would only allow oppositely charged ions pass through, and so have a permselectivity value of 1 .

227 The permselectivity measured in terms of transport number were obtained from chronopotentiometry tests as previously described. ${ }^{41}$ The setup for the chronopotentiometry tests is shown in Error! Reference source not found.a. Prior to the measurements, the sodium

230 form of the membrane sample was immersed in $0.1 \mathrm{M} \mathrm{NaCl}$ for $24 \mathrm{~h}$. The membrane sample was held using a plastic sandwich with a round exposed area of $0.196 \mathrm{~cm}^{2}$. The reference and sensing electrodes used were $\mathrm{Ag} / \mathrm{AgCl}$ electrodes, while the working and counter electrodes used were platinum mesh electrodes. $50 \mathrm{~mL} 0.1 \mathrm{M} \mathrm{NaCl}$ solution was filled into each compartment of the test cell. The solution was stirred continuously throughout the tests. Acquisition of the chronopotentiometric curves was achieved using a PGSTAT302N potentiostat/galvanostat (Metronohm Autolab, Netherlands; Software: Nova1.11), operated in galvanostatic mode at a current of $4 \mathrm{~mA}$. The transition time was determined at the point of inflection of the chronopotentiometric curves. The modified Sand equation was used to obtain the permselectivity (Equation (4)): ${ }^{42}$ 


$$
P=\frac{|z| \cdot F \cdot D^{0.5} \cdot \pi^{0.5} \cdot C}{2\left(1-t_{\mathrm{i}}\right) \cdot \frac{I}{A} \cdot \tau^{0.5}}
$$

240 where $P$ is the permselectivity, $|z|$ is the absolute charge of the sodium ion $(|+1|), F$ is the

241 Faraday constant $\left(96,485 \mathrm{~A} \mathrm{~s} \mathrm{~mol}^{-1}\right), D$ is the diffusion coefficient $\left(1.48 \times 10^{-5} \mathrm{~cm}^{-2} \mathrm{~s}^{-1}\right)$ and $t_{\mathrm{i}}$

242 is the transport number (0.396) of the sodium ion in $0.1 \mathrm{M} \mathrm{NaCl},{ }^{42} C$ is the concentration of

243 the sodium ions $(0.1 \mathrm{M}), I$ is the applied current $(4 \mathrm{~mA}), A$ is the exposed membrane area

$244\left(0.196 \mathrm{~cm}^{2}\right)$, and $\tau$ is the transition time. The chronopotentiometry measurements were

245 performed in duplicates using two different pieces from the same membrane sheet. The

246 transition time was measured in both directions (positive and negative current) to eliminate any

247 possible effects of electrode inequivalence. The permselectivity values were obtained as an

248 average of four runs.

249

250

251

252

253

254

255 
a

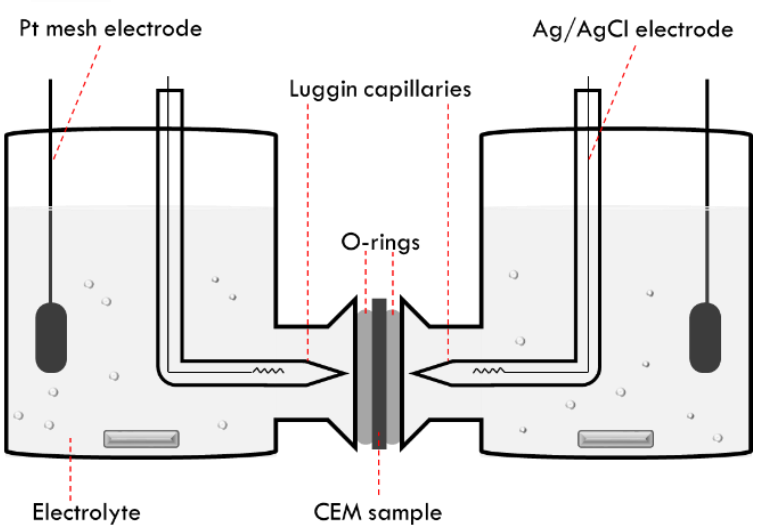

b

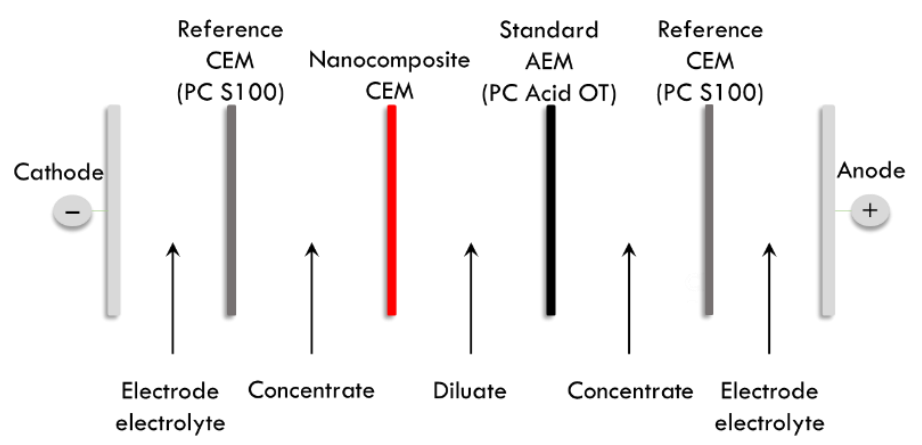

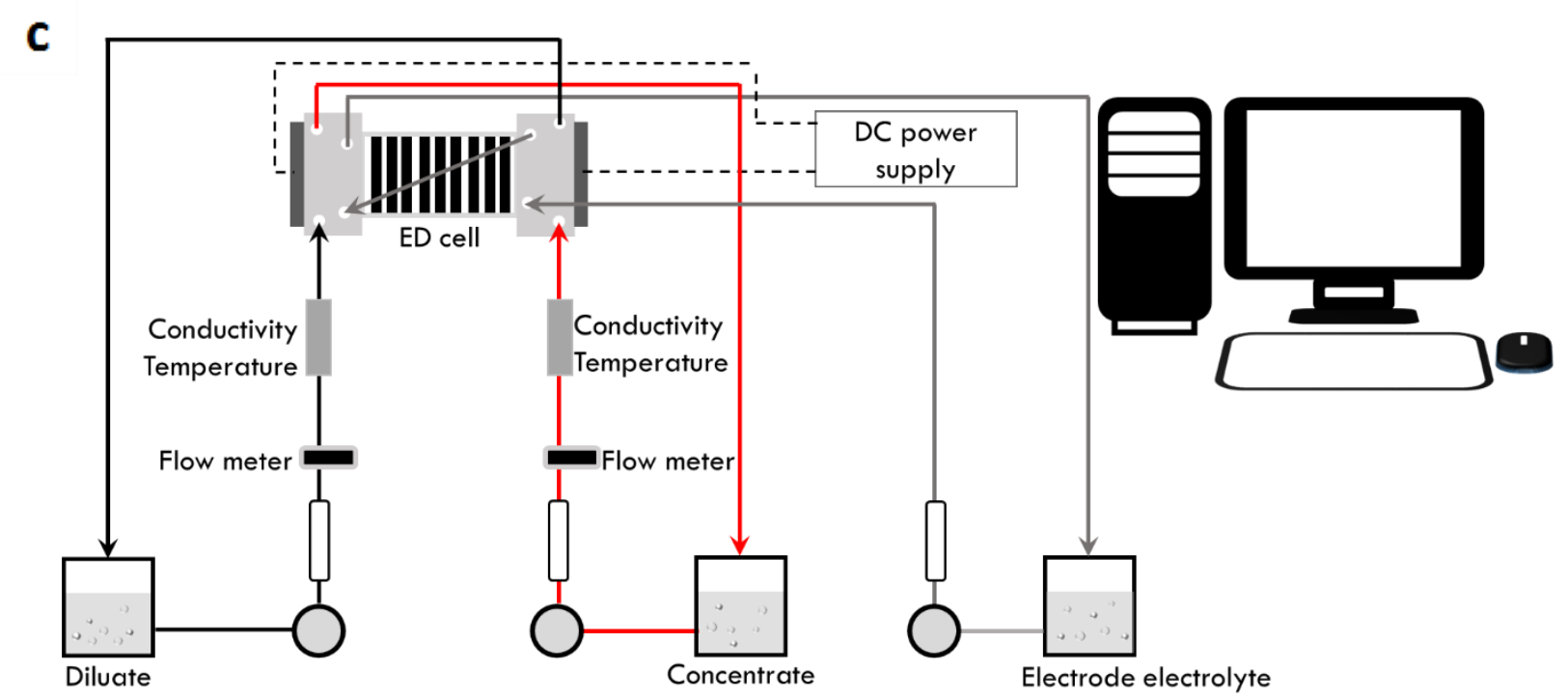

Figure 5 (a) Electrochemical test cell used for chronopotentiometry and electrochemical impedance spectroscopy measurements. (b) Membrane stack assembly in ED cell. (c) Process diagram of the electrodialysis experiment setup.

257 The membrane area resistance was measured by electrochemical impedance spectroscopy 258 (EIS) using the test cell as shown in Error! Reference source not found.a. In this case, 50 $\mathrm{mL} 1.0 \mathrm{M} \mathrm{NaCl}$ was filled into each compartment. There was no stirring of the solutions during

260 the tests. Before the EIS tests, the membrane was soaked in $1.0 \mathrm{M} \mathrm{NaCl}$. The EIS tests were run using a PGSTAT302N, a potentiostat/galvanostat with FRA32M frequency response analyzer. All tests were performed using a $0.1 \mathrm{~mA}$ amplitude AC signal at 50 different

263 frequencies from $1 \mathrm{mHz}$ to $1 \mathrm{kHz}$. The EIS measurements were performed in duplicates using 
the same membrane pieces as in the chronopotentiometry tests. The area resistance was obtained after equivalent circuit fitting and after correction with the resistance of the empty cell. The exposed membrane area was $0.196 \mathrm{~cm}^{2}$ in all tests. Equation (5) was used to determine

267 the area resistance of the membrane samples.

$$
R_{\mathrm{A}}=\left(R_{\mathrm{m}+\mathrm{sol}}-R_{\mathrm{sol}}\right) \cdot A
$$

268 where $R_{\mathrm{A}}$ is the membrane area resistance, $R_{\mathrm{m}+\mathrm{sol}}$ is the resistance of the membrane in the

269 solution, $R$ sol is the resistance of the empty cell, and $A$ is the membrane area.

\subsection{Electrodialysis Assessment}

271 Electrodialysis (ED) tests were conducted to assess the salt removal rate, current efficiency and

272 energy consumption of the fabricated nanocomposite CEMs. The electrodialysis experiments

273 were performed using an electrodialysis setup which consisted of a PCCell Micro BED System

274 (see Error! Reference source not found.c for schematic diagram) with three closed-loop

275 liquid circulation circuits for diluate, concentrate and electrode electrolyte solutions.

276 Sensors for electrical conductivity (EC), temperature and flow in the diluate and concentrate

277 circuits were connected to a control system, operated by a computer. This allowed for the control, monitoring and data acquisition of the process. The liquids were contained in graduated polypropylene cylinders and were pumped through the ED cell. The cell holder contained the 280 electrodes.

281 From each sample type, the nanocomposite CEM (cut into $40 \mathrm{~mm} \times 60 \mathrm{~mm}$ rectangular shape) was punched and assembled in a cell stack together with a standard AEM (type PC Acid 60

283 OT) (Error! Reference source not found.b). An additional CEM (PC S100) was included at 284 the cathode side to prevent the migration of sulfate ions from the cathode chamber into the 285 concentrate compartment. The experiments were performed in batch mode with circulated 

diluate and concentrate solutions, consisting of $\mathrm{NaCl}$ solution with initial concentration of 0.1

287 M (brackish water). A DC current was applied between the electrodes, which led to flow of the anions $\left(\mathrm{Cl}^{-}\right)$through the AEM to the concentrate compartment adjacent to the anode and flow of the cations $\left(\mathrm{Na}^{+}\right)$to the concentrate compartment adjacent to the cathode.

290 The decrease of EC in the diluate due to decrease of salt concentration and the increase of 291 conductivity in the concentrate due to increase of salt concentration, was recorded by the 292 control system. The parameters of the experimental setup are shown in Table 2.

293 For each nanocomposite CEM sample, 3 consecutive ED runs were performed. For 294 comparison, an additional run with a standard reference CEM (type PC S100) at the position 295 of the sample nanocomposite CEM, was performed. Each ED run generated a data set of EC, 296 temperature and flow rate for diluate and concentrate, as well as voltage and current values, 297 collected for $2 \mathrm{~s}$ time intervals. Volumes were read manually every $5 \mathrm{~min}$.

$298 \mathrm{NaCl}$ concentrations were automatically calculated from the EC of the solution assuming direct 299 proportionality. The EC was measured by electrical inductive conductivity sensors (JUMO 300 CTI-500, from JUMO, Germany). The EC values were automatically temperaturecompensated to $25^{\circ} \mathrm{C}$. Prior to each experiment, the diluate and concentrate circuits were rinsed with DI water until the conductivity dropped below $0.1 \mathrm{mS} / \mathrm{cm}$. For each run, fresh $\mathrm{NaCl}$ solutions were filled into the diluate and concentrate circuits until conductivities corresponding to $0.1 \mathrm{M} \mathrm{NaCl}$ were reached. The electrode electrolyte was also replaced at every new experiment. 
Table 2 Parameters for electrodialysis experiment

\begin{tabular}{ll}
\hline Parameter & Value \\
\hline Active membrane area & $6.5 \mathrm{~cm}^{2}$ \\
Spacer thickness & $0.4 \mathrm{~mm}$ \\
Thickness of PC S100 CEM (wet condition) & $0.072 \mathrm{~mm}$ \\
Thickness of PC Acid OT AEM (wet condition) & $0.95 \mathrm{~mm}$ \\
Electrode electrolyte & $8.5 \% \mathrm{Na}_{2} \mathrm{SO}_{4}$ solution \\
Diluate (volume and initial concentration) & $100 \mathrm{~mL} 0.1 \mathrm{M} \mathrm{NaCl}$ \\
Concentrate (volume and initial concentration) & $100 \mathrm{~mL} 0.1 \mathrm{M} \mathrm{NaCl}$ \\
Applied Voltage (Max) & $30 \mathrm{~V}$ \\
Applied Current (Max) & $0.65 \mathrm{~A}$ \\
Diluate flowrate & $6.5-7.2 \mathrm{~L} / \mathrm{h}$ \\
Concentrate flowrate & $3.7-4.5 \mathrm{~L} / \mathrm{h}$ \\
\hline
\end{tabular}

310 The current and voltage were automatically adjusted by the computer. A low resistance of the

311 system limits the current to $0.65 \mathrm{~A}$, while the voltage is below $30 \mathrm{~V}$. A high resistance limits

312 the voltage to $30 \mathrm{~V}$, while the current falls below $0.65 \mathrm{~A}$. The reason for constant current is

313 that the ED experiments are easily controlled and evaluated with constant current, while a

314 voltage limit is necessary in order to protect the cell from overheating and to avoid too high

315 voltages at the electrochemical interfaces.

316 The current was started after 2 min stabilization of the flow. After a run time of $40 \mathrm{~min}$, the

317 current was switched off and the system was allowed to settle down for another 6 min. Three

318 consecutive experiments were performed immediately one after another without disassembly

319 of the cell. The overall charge (in units of Faraday: $1 \mathrm{~F}=96,487 \mathrm{~A} \mathrm{~s} \mathrm{~mol}^{-1}$ ) was automatically

320 evaluated and stored by the measurement and control software. Evaluation of the current

321 efficiency and power consumption was done using Equations (6) and (7) respectively.

$$
\text { Current efficiency }=\frac{V_{\mathrm{D}}\left|\Delta C_{\mathrm{D}}\right| F}{\int I \mathrm{~d} t}
$$




$$
\text { Power consumption }(\mathrm{kJ} / \mathrm{g})=\frac{\int U I \mathrm{~d} t}{V_{\mathrm{D}}\left|\Delta C_{\mathrm{D}}\right|}
$$

323 where $V_{\mathrm{D}}$ is the volume of the diluate, $\Delta C_{\mathrm{D}}$ is the change in concentration of the diluate, $F$ is

324 Faraday constant $96,487 \mathrm{~A} \mathrm{~s} \mathrm{~mol}^{-1}, I$ is the applied current, $U$ is the applied voltage and $t$ is the 325 duration of the experiment.

326 The salt removal was also evaluated according to the Equation (8) below:

$$
\text { Salt removal }(\%)=\frac{C_{i}-C_{f}}{C_{i}} \times 100
$$

327 where $C_{i}$ and $C_{f}$ are the initial and final salt concentrations of the diluate solution.

\section{$328 \quad 3 \quad$ Results and Discussion}

\subsection{Nanocomposite Membrane Stability}

330 Attempts were made to fabricate nanocomposite IEMs with nanomaterial loadings higher than 45 wt.\%. This was done with the objective of increasing the density of ion exchange functional groups in the nanocomposite CEMs. In line with this, SrGO/PVDF nanocomposite CEMs with SrGO loadings of 55 wt.\% and 65 wt.\% were prepared. We however discovered that these membranes (with loadings higher than 45 wt.\%) had multiple cracks right after the temperature-induced phase inversion. Therefore the SrGO/PVDF_55 and SrGO/PVDF_65 nanocomposite CEMs were unfit for use as membranes for electromembrane processes. However, the nanocomposite CEMs with loadings of $45 \mathrm{wt} . \%$ were in good shape, without any cracks (see Figure 6). As a result, only SGO/PVDF_45 and SrGO/PVDF_45 were considered for characterization. 

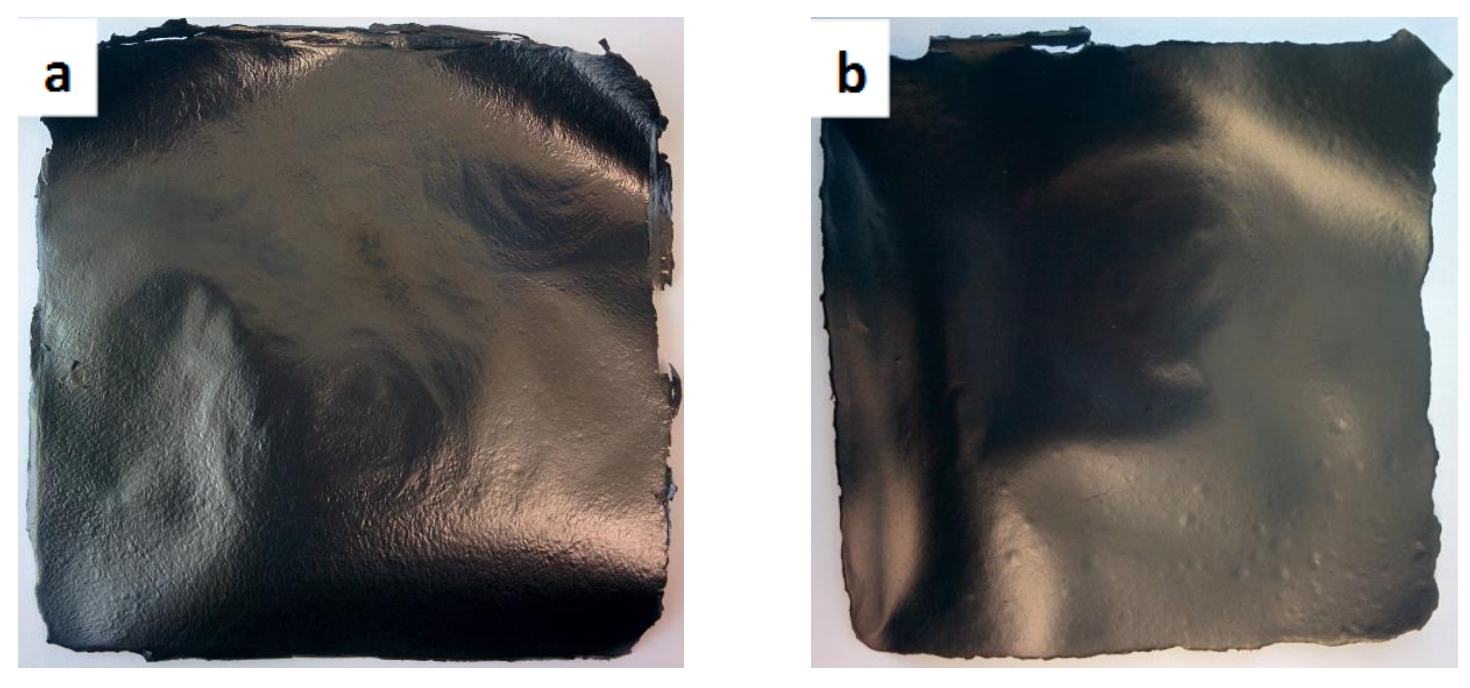

Figure 6 Fabricated nanocomposite CEMs: (a) SGO/PVDF_45; (b) SrGO/PVDF_45. Only the nanocomposite CEMs with 45 wt.\% loadings were in good shape without cracks.

\subsection{FTIR and Raman spectroscopy analyses}

342 The Raman spectroscopy analyses of the GO, rGO, SGO and SrGO are shown in Error!

343 Reference source not found.a. The D and $\mathrm{G}$ bands at $\sim 1340 \mathrm{~cm}^{-1}$ and $\sim 1585 \mathrm{~cm}^{-1}$, respectively,

344 are typical for graphene-based nanomaterials. ${ }^{43-45}$ The appearance of these bands, therefore,

345 confirms that the nanosheets are graphene-based. The intensity of the ratio of the D and G

346 bands $\left(I_{\mathrm{D}} / I_{\mathrm{G}}\right)$ for $\mathrm{GO}$ is 1.029 and 1.015 for $\mathrm{rGO}$. The decrease in $\mathrm{I}_{\mathrm{D}} / \mathrm{I}_{\mathrm{G}}$ ratio, although by a

347 small margin, suggests a lower amount of basal plane defects in the rGO sample. ${ }^{46}$

348 The FTIR spectroscopy analyses are shown in Error! Reference source not found.b and c.

349 The typical spectrum and characteristic bands for GO are displayed in Figure 7b. After

350 reduction to $\mathrm{rGO}$, the peaks for the oxygen-containing functional groups were absent. The

351 transformation of GO to $\mathrm{rGO}$ is confirmed by the absence of the $\mathrm{OH}$ deformation peak and C-

352 O stretch peaks in the rGO spectra (Error! Reference source not found.b). ${ }^{47-49}$ The results of

353 the FTIR analyses are in agreement with available literature on GO and rGO. ${ }^{50,51}$ In Error! 
354 Reference source not found.c, sulfonic group bands are present for the modified SGO, SrGO,

356 This confirms the presence of sulfonic groups in the modified nanosheets and fabricated

357 nanocomposite CEMs.

a

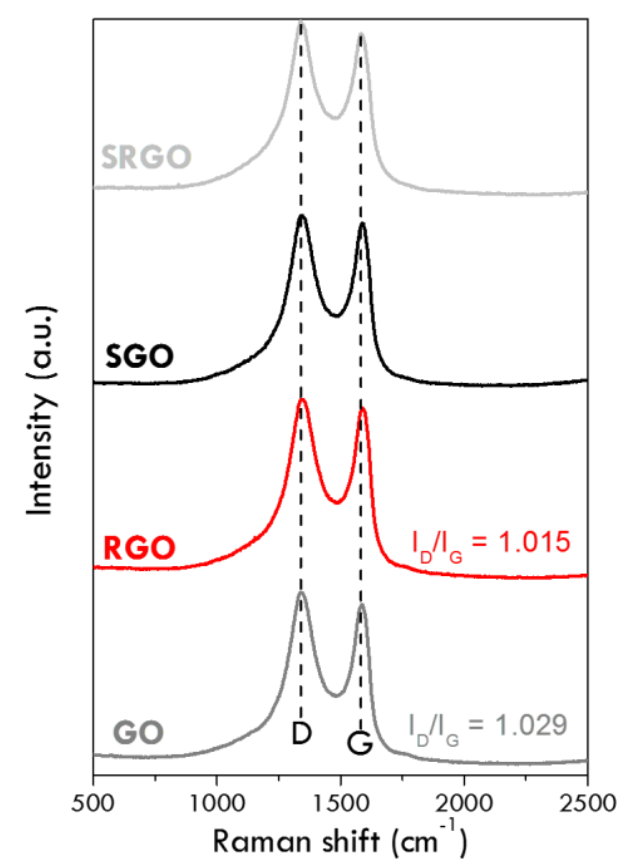

b

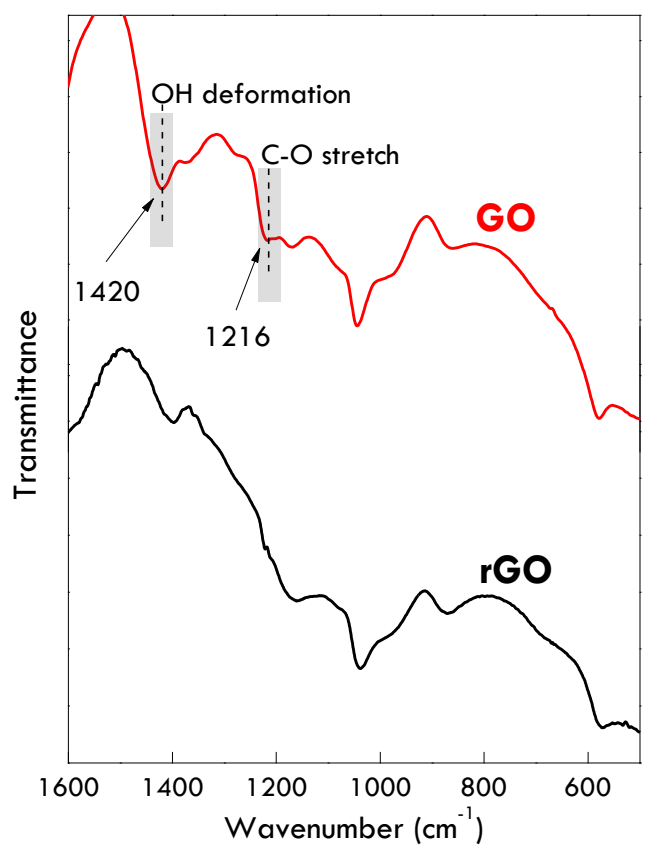

C

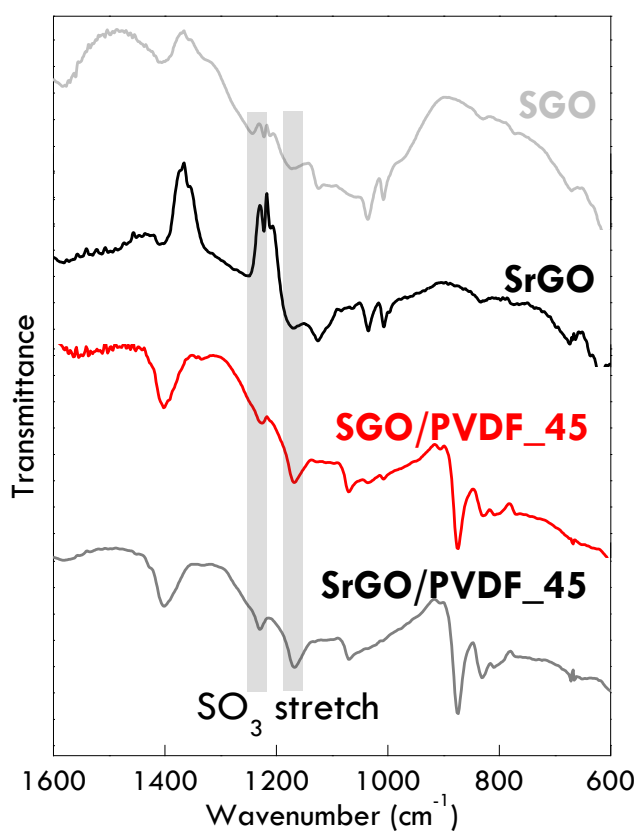

Figure 7 (a) Raman spectroscopy of nanomaterials. (b) FTIR spectroscopy of GO and rGO. 358

(c) FTIR spectroscopy of modified nanosheets and fabricated nanocomposite CEMs

\subsection{Structural and Elemental Analysis of Prepared Membranes}

360 Figure 8 shows the top surface and cross-sectional views of the membrane samples. The

361 morphologies of the SGO/PVDF_45 and SrGO/PVDF_45 differ from that of the plain PVDF

362 membrane, owing to the high loading of SGO and SrGO nanosheets which represent 45 wt.\%

363 of the nanocomposite CEMs. Cross-sectional images revealed a stacked structure in the

364 SGO/PVDF_45 and SrGO/PVDF_45, while the plain PVDF membrane had a typical globular

365 structure. From the images, it can be seen that the 2D nanosheets of SGO and SrGO were well 
oriented and stacked in layers during the casting and setting process and resulted in denser

367 membranes with a visible stacked-sheet structure. The thickness of the SGO/PVDF_45 was 99

$368 \pm 4 \mu \mathrm{m}$, while that of the SrGO/PVDF_45 was $71 \pm 2 \mu \mathrm{m}$. The SGO/PVDF_45 was thicker

369 than the SrGO/PVDF_45, although both their casting solutions had a similar composition in

370 terms of proportion of polymer, solvent and nanomaterial used (i.e. 1.5 g PVDF: 45 mL NMP:

$3711.2 \mathrm{~g}$ nanomaterial). Moreover, the same volume of casting solution was used to cast both types

372 of membranes. The lower thickness observed for SrGO/PVDF_45 can be attributed to the rGO

373 nanosheets. In producing rGO, the oxygen containing functional groups were removed from

374 GO; resulting in a reduction in the interlayer distance between the nanosheets and a higher

375 tendency for restacking. ${ }^{35}$ This reduced interlayer distance resulted in SrGO/PVDF CEMs with

376 a lower thickness than their SGO counterparts.

377 EDS analyses show the elemental composition of the membranes (Figure 9). The sulfur map

378 confirms the presence of $-\mathrm{SO}_{3}{ }^{-}$functional groups in both types of nanocomposite CEMs.

379 Furthermore, the absence of hotspots demonstrates that there was no agglomeration of the SGO

380 or SrGO nanosheets in the nanocomposite CEMs. Since nanomaterial agglomeration can lead

381 to sites of failure in nanocomposite membranes, ${ }^{56,57}$ the absence of nanomaterial agglomeration

382 suggests membrane stability. Nevertheless, it was found that uniform dispersion of SrGO in

383 the SrGO/PVDF_45 CEM was achieved as shown by the absence of aggregates in the EDS

384 map (Figure 9k). This confirmed that SrGO was thoroughly dispersed in the casting solution

385 despite its lower concentration of oxygen functional groups.

386

387

388

$22 \mid \mathrm{P}$ a g e 

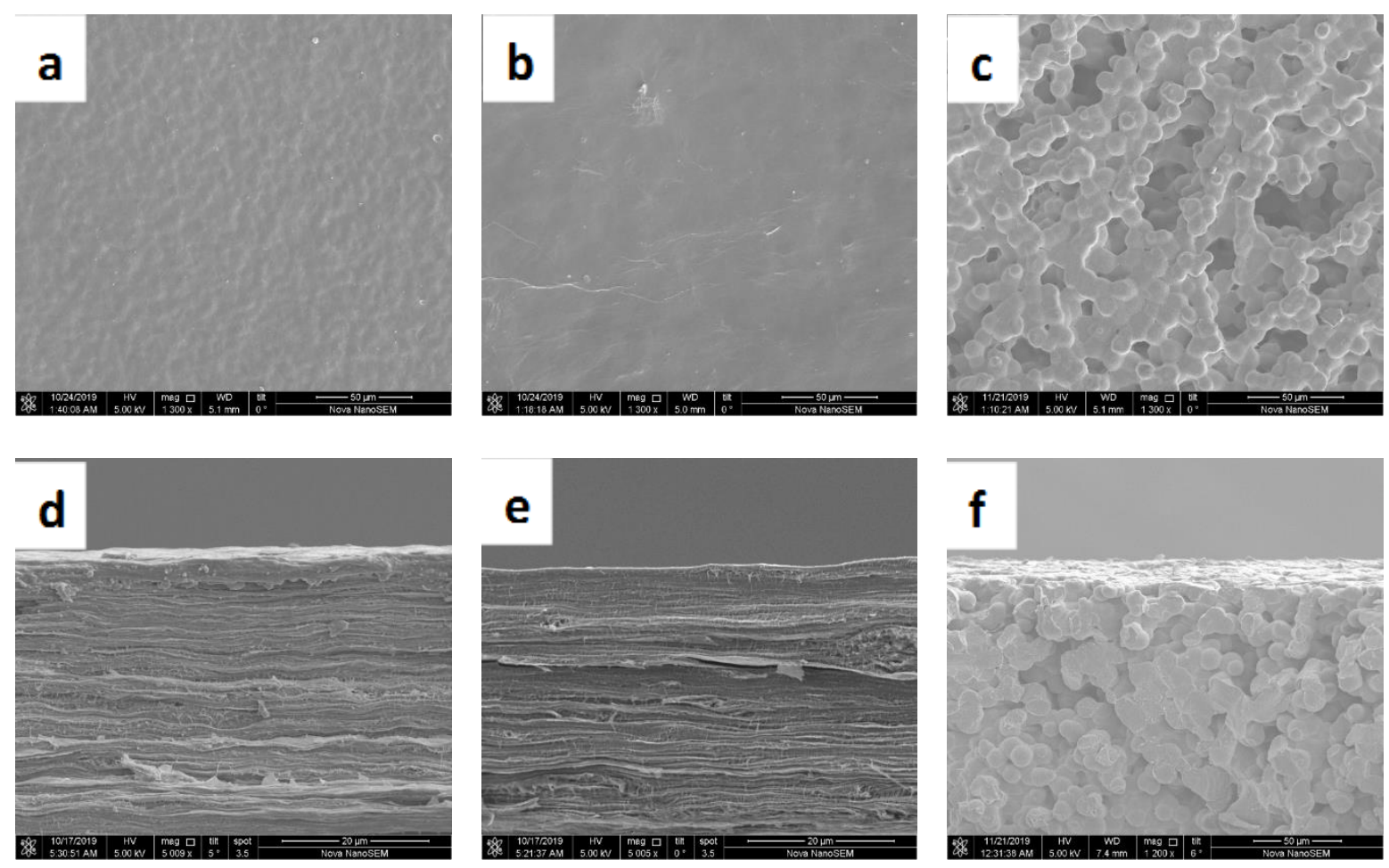

Figure 8 SEM images of fabricated membranes. Top surface views of (a) SGO/PVDF_45; (b) SrGO/PVDF_45; (c) plain PVDF. Cross-sectional views of (d) SGO/PVDF_45; (e) SrGO/PVDF_45; (f) plain PVDF. 

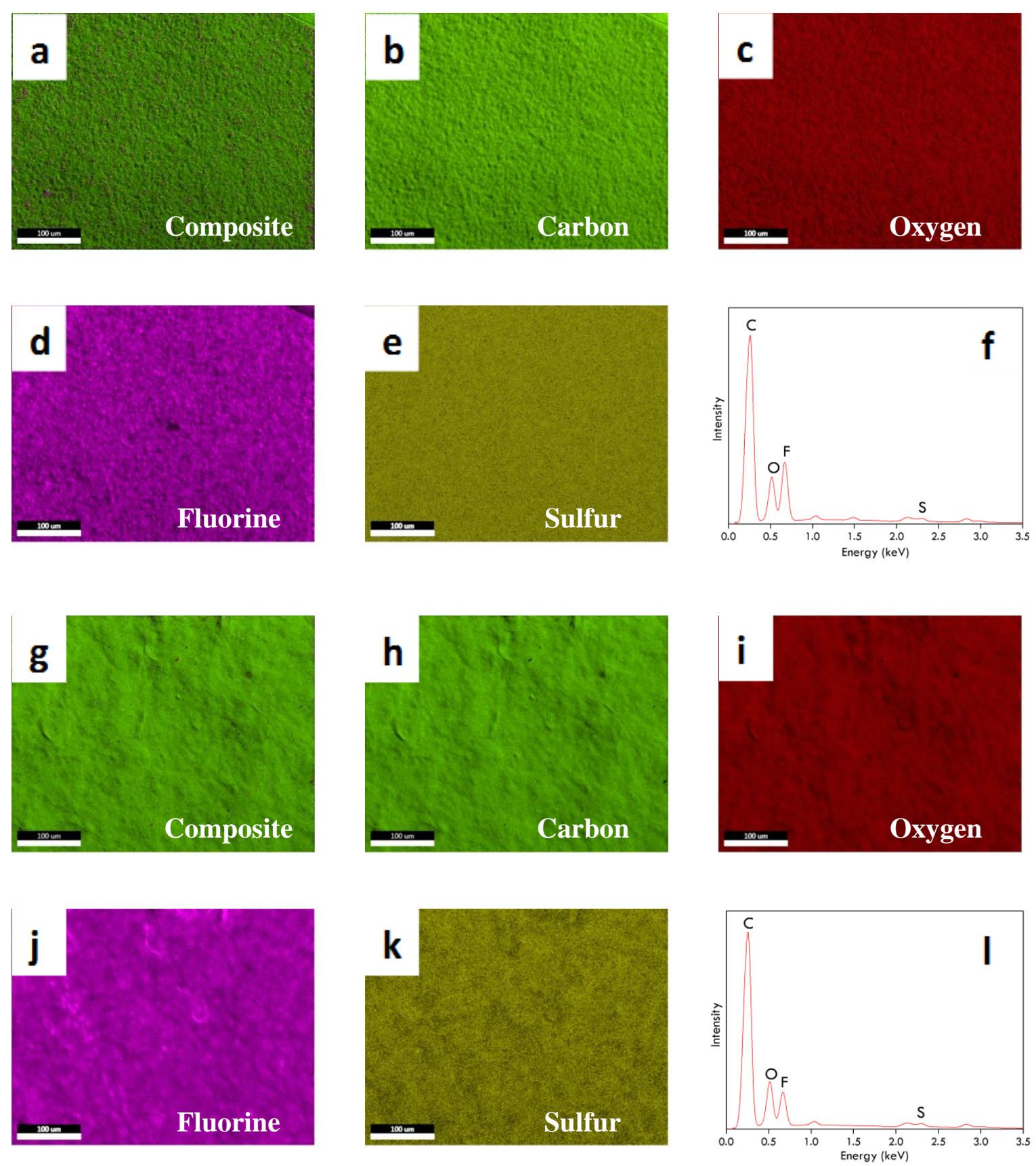

Figure 9 Composite and elemental maps and EDS spectrum: (a-f) for SGO/PVDF_45; (g-i) for SrGO/PVDF_45.

\subsection{Wettability and Electrochemical Properties of Membranes}

399 The water uptake results are shown in Table 3. It is found that SrGO/PVDF_45 showed

400 significantly lower water uptake than SGO/PVDF_45. This is because the SrGO/PVDF_45

401 surface was less hydrophilic because of the rGO component, which possessed lesser amounts 
402 of oxygen functional groups as compared to GO, so less hydrogen bonds were formed on the surface of the materials in the aqueous environment. ${ }^{58}$

Table 3 Wettability properties and IEC of nanocomposite CEMs

\begin{tabular}{lrrr}
\hline Nanocomposite CEM & $\begin{array}{r}\text { Water uptake } \\
(\%)\end{array}$ & $\begin{array}{r}\text { Linear swelling } \\
\text { ratio }(\%)\end{array}$ & IEC (meq/g) \\
\hline SGO/PVDF_45 & $255.10 \pm 0.21$ & $1.51 \pm 0.01$ & $0.61 \pm 0.03$ \\
SrGO/PVDF_45 & $60.14 \pm 0.01$ & $0.84 \pm 0.01$ & $0.54 \pm 0.02$ \\
\hline
\end{tabular}

404

405 The fabricated nanocomposite membranes were shown to have low linear selling ratios (Table

406 3), similar to results obtained for a previously reported CEM. ${ }^{22}$ A lower linear swelling ratio is 407 observed for the SrGO/PVDF_45 in comparison to the SGO/PVDF_45. This is in line with the 408 water uptake results, as GO is more hydrophilic than $\mathrm{rGO}$ and is expected to swell considerably 409 more than $\mathrm{rGO}^{31}$ The presence of the nanomaterials in both SGO/PVDF_45 and 410 SrGO/PVDF_45 allows more interfacial interactions within the porous membrane structure and 411 also acts as pore fillers that increase the stiffness of the nanocomposite membrane, thus 412 resulting in lower linear swelling ratio than the more swelling non-nanocomposite 413 counterpart. ${ }^{59}$

414 Water contact angle measurement results are shown in Error! Reference source not found.a.

415 The surfaces of SrGO/PVDF_45 and SGO/PVDF_45 are found to be hydrophilic, whereas the 416 surface of PVDF is hydrophobic. This is expected due to the hydrophilic nature of the GO as 417 well as chemically reduced rGO nanosheets. Moreover, GO has more oxygen containing 418 functional groups than rGO, which also explains why the surface of SGO/PVDF_45 was more 419 hydrophilic with lower water contact angle than that of the SrGO/PVDF_45. 
a

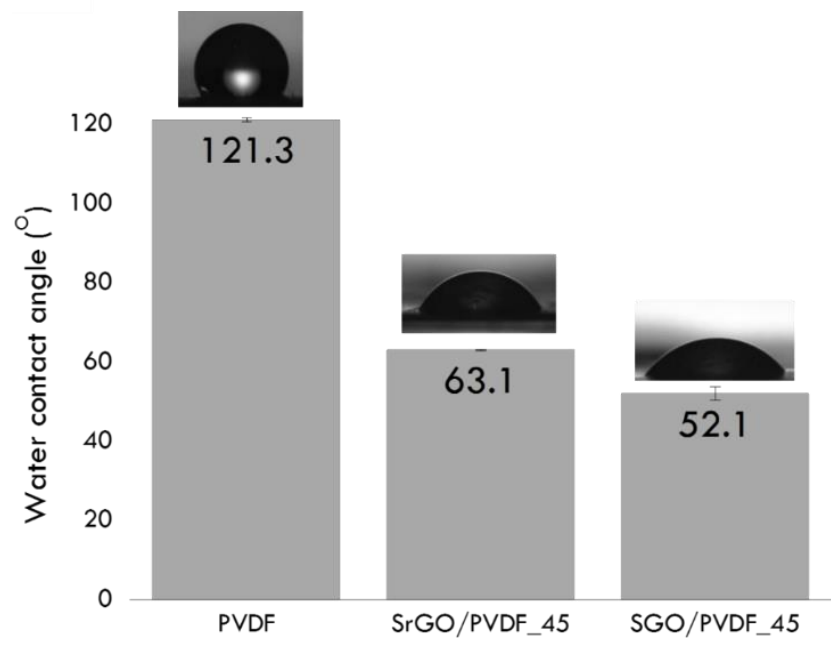

b

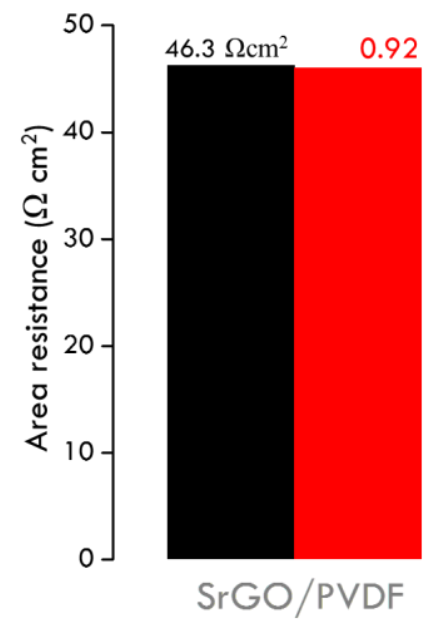

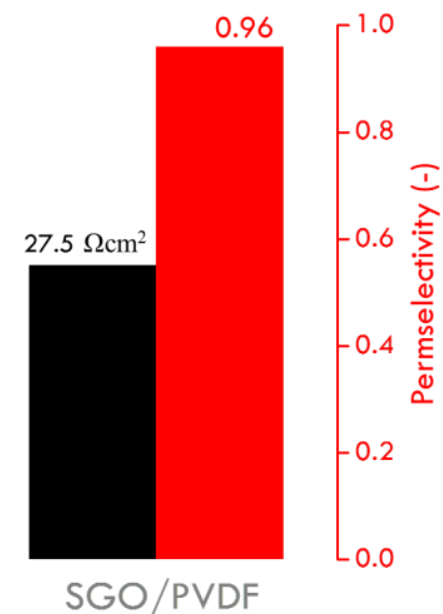

Figure 10 (a) Water contact angle results for PVDF, SrGO/PVDF and SGO/PVDF membranes. (b) Area resistance and permselectivity of the SGO/PVDF_45 and SrGO/PVDF_45 nanocomposite CEMs.

422

423 The measured IEC values are shown in Table 3. The IEC value of SGO/PVDF_45 is in line

424 with previously reported work. ${ }^{22}$ Both nanocomposite CEMs exhibited relatively low IEC but

425 were within close proximity to values of some commercial CEMs reported in literature i.e.

426 CSMCRI HGC heterogeneous CEM $(0.67-0.77 \mathrm{meq} / \mathrm{g}){ }^{60} \mathrm{SGO} / \mathrm{PVDF}$ 45 had a higher IEC

427 than SrGO/PVDF_45. This may be due to the presence of more negatively charged carboxylic

428 functional groups on the planes of GO nanosheets, additional to the sulfonic groups, which can

429 contribute to ion exchange.

430 For SGO/PVDF_45, the permselectivity and area resistance values were found to be $0.96 \pm$ 4310.04 and $27.5 \pm 16.5 \Omega \mathrm{cm}^{2}$, respectively. While the permselectivity and area resistance of the 432 SrGO/PVDF_45 CEMs were $0.92 \pm 0.04$ and $46.3 \pm 3.2 \Omega \mathrm{cm}^{2}$, respectively (see Error! 433 Reference source not found.b). As the nanocomposite CEMs were made of similar 434 composition, except for the type of nanomaterial, the difference in the permselectivity and area 435 resistance values can be attributed to the differences between the nanomaterial additives (i.e. 
436 SGO or SrGO). Since SGO has been confirmed to be more hydrophilic and also carries extra 437 negatively charged groups such as hydroxyl groups for ion exchange, the impact on the 438 permselectivity and area resistance is expected to be more when compared to SrGO. This may 439 explain why SGO/PVDF_45 exhibited higher permselectivity and lower area resistance than 440 SrGO/PVDF_45. Moreover, the smaller interlayer distance between the rGO nanosheets 441 resulting from chemical reduction alongside with lower swelling may restrict the passage of 442 ionic species through the membrane which is therefore reflected in the higher area resistance 443 of SrGO/PVDF_45. ${ }^{35}$ The area resistance of the SGO/PVDF_45 CEM was higher than 444 previously reported. ${ }^{22}$

\subsection{Assessment of the Nanocomposite CEMs in an Electrodialysis Cell}

446 Error! Reference source not found.b shows the change in currrent with time for the CEMs

447 during the electrodialysis tests. It can be seen that the current decreased with time as a result of 448 the diminishing conductivity of the diluate compartment. When the diluate conductivity 449 decreased, the cell resistance became higher and the voltage increased up to the limit voltage. 450 Beyond this point, the voltage was kept constant by decreasing the current. Starting from 451 identical initial salinity values of the $\mathrm{NaCl}$ solution, the electrical conductivity (EC) of the diluate steadily decreased upon starting of current and the EC of the concentrate increased which is expected for an electrodialysis process. ${ }^{40}$ When the current was cut, the EC remained constant which suggests conserved structural integrity of the membranes and no mixing of the compartments through membrane defects. The concentration profile for the diluate and concentrate sections is displayed in Error! Reference source not found.c. The rate at which the salt concentration changed was almost linear for all three CEMs, and plateaued as time progressed. 
a

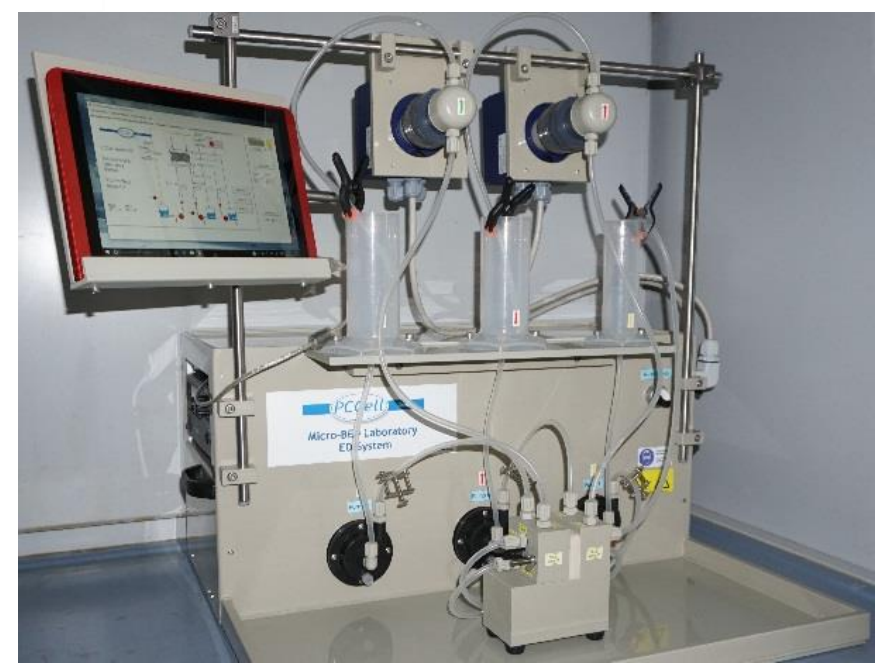

\section{C}

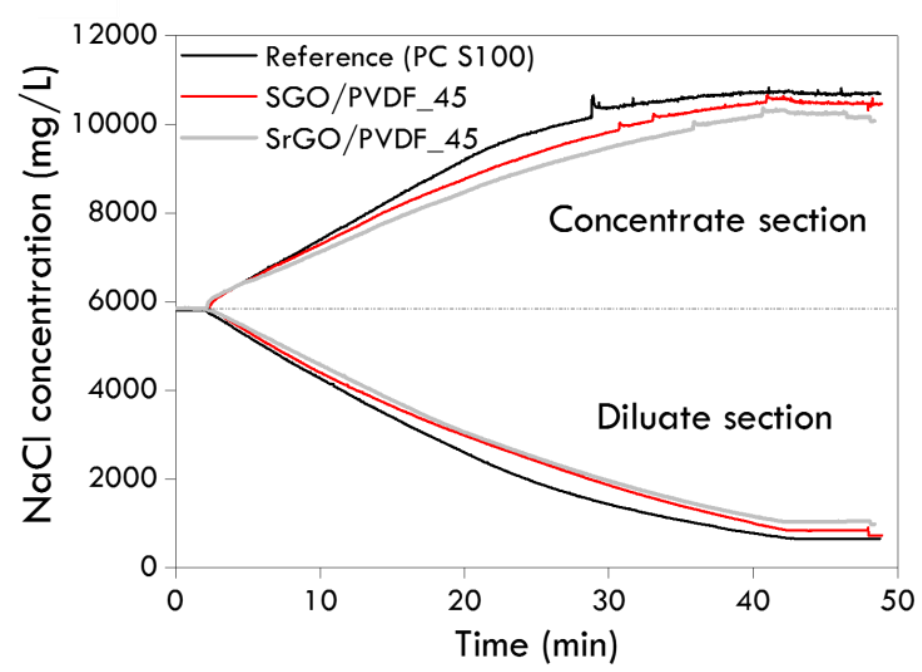

b

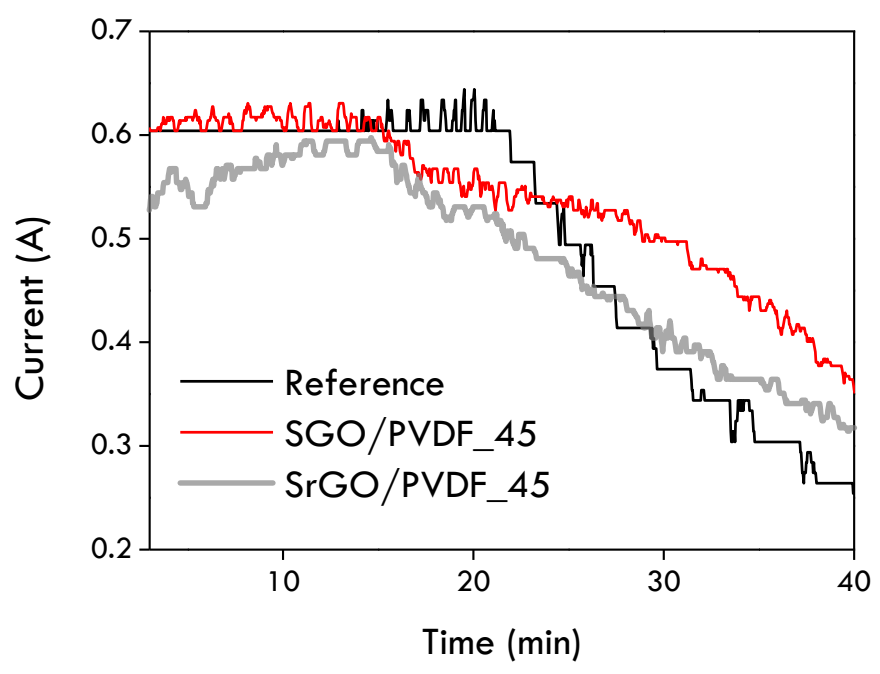

d

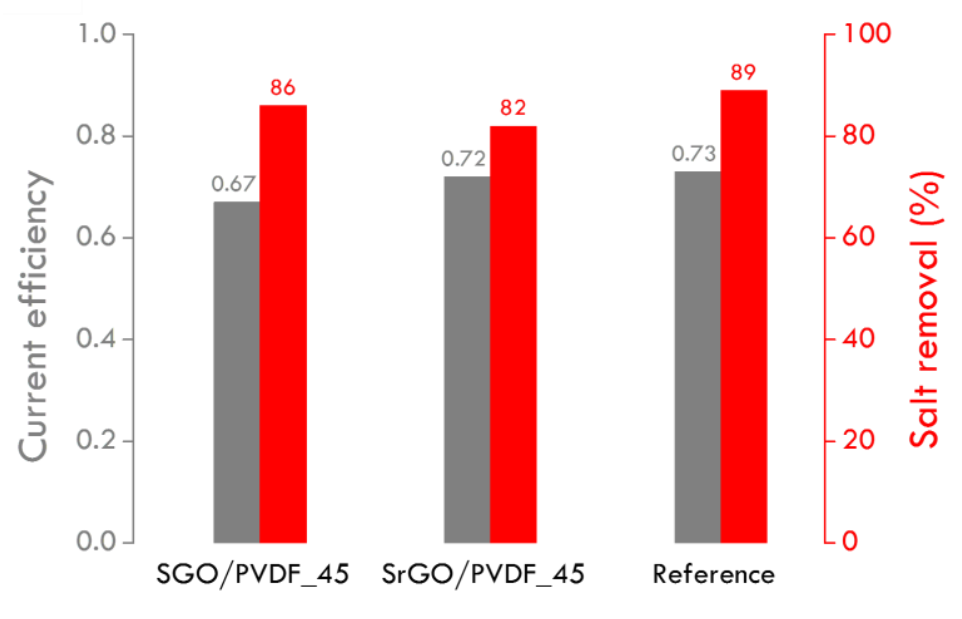

Figure 11 (a) Experimental setup for ED tests (Source: PCCell GmbH, Lebacher Str. 60, 66265 Heusweiler, Germany). (b) Current - time curves for the electrodialysis tests with different CEMs. (c) Salt concentration changes in diluate and concentrate during electrodialysis experiments with different CEMs. (d) Current effficiency and salt removal of fabricated nanocomposite CEMs and reference CEM during electrodialysis test.

462 The suitability of the fabricated nanocomposite CEMs for electrodialysis is evaluated by

463 determining the current efficiency, salt removal rate and energy consumption. These

464 parameters are influenced by the membrane properties and the operating conditions of the 
experiment. Current efficiency values of $0.67 \pm 0.05,0.72 \pm 0.05$ and 0.73 were obtained for

467 (grey columns in Error! Reference source not found.d). The current efficiency of the SrGO/PVDF_45 was higher by 0.05 than that of the SGO/PVDF_45, and comparable to the reference CEM. This higher current efficiency could be attributed to the improved electronic conductivity of rGO. The high electronic conductivity or rGO has been well reported in literature, and is considerably larger than that of GO. ${ }^{61}$ Whereas, GO has more lattice imperfections and attached functional groups on its planes, which explains the vastly lower electronic conductivity. As an electromembrane such as cation exchange membrane, its overall separation performance not only relies on the relative ionic affinity of the ionic species being separated to the polymer, but also relates to the current efficiency which is based on the electrical potential generated by passing given current through the membrane. ${ }^{62,63}$ The more electronic conductive membrane materials will enhance such electrical potential. The presence of rGO in SrGO/PVDF_45 could enhance the current utilization and lead to the increased current efficiency.

The average salt removal results are displayed in Error! Reference source not found.d (red columns). The salt removal results show comparable performance of the fabricated nanocomposite CEMs ( $86 \pm 2 \%$ for SGO/PVDF_45 and $82 \pm 1 \%$ for SrGO/PVDF_45) and the reference (PC S100) CEM (89\%). These results demonstrate that the fabricated nanocomposite CEMs are as effective as the commercial CEM during elctrodialysis desalination runs. $\mathrm{kJ} / \mathrm{g})$, SGO/PVDF_45 $(67.1 \pm 3.9 \mathrm{~kJ} / \mathrm{g})$ and SrGO/PVDF_45 $(68.3 \pm 3.9 \mathrm{~kJ} / \mathrm{g})$ during electrodialysis tests. The energy consumption of salt removal for both nanocomposite CEMs were at similar levels, although higher than the value recorded for the reference CEM. As the

489 IEC of these nanocomposite CEMs are proportional to the charge carrying-nanomaterials 29 |P a g e 
loadings, which is limited to $45 \%$ at present, further increase of either the charge density or the

491 loading of the nanomaterials in the CEMs will increase its IEC, and could reduce the energy

492 consumption.

Table 4 Energy consumption for salt removal for fabricated nanocomposite CEMs and the reference CEM

\begin{tabular}{lr}
\hline CEM & Energy consumption $(\mathrm{kJ} / \mathrm{g})$ \\
\hline SGO/PVDF_45 & $67.1 \pm 3.9$ \\
SrGO/PVDF_45 & $68.3 \pm 3.9$ \\
Reference (PC S100) & 49.0 \\
\hline
\end{tabular}

493

494 The SrGO/PVDF_45 CEM demonstrated some advantagous properties with a 7.5\% higher 495 current efficiency, as well as the $0.67 \%$ less swelling than that of SGO/PVDF_45 CEM.

496 However, the removal of the oxygen functional groups led to rGO nanosheets with smaller

497 interlayer space, consequently increasing restrictions in the nanoconducting channels for ion 498 transport as demonstrated by the lower area resistance and permselectivity values. Both 499 nanocomposite CEMs demonstrated encouraging results for electrodialysis.

\section{Conclusions}

501 Modified GO and rGO nanosheets were incorporated into a non-charged membrane matrix to 502 create nanocomposite CEMs for electrodialysis. GO and rGO were modified to sulfonic group503 bearing SGO and SrGO, using a combination of 3,4-dihydroxy-L-phenylalanine (L-DOPA) 504 and poly(sodium 4-styrenesulfonate) (PSS). 45 wt.\% of SGO, and 45, 55, and 65 wt. \% of 505 SrGO, were added into PVDF matrix to produce SGO/PVDF and SrGO/PVDF nanocomposite 506 CEMs, respectively. A mold-casting technique was used to fabricate the nanocomposite CEMs. 507 It was found that only the nanocomposite CEMs with 45 wt.\% were crack-free and were 508 appropriate for use as CEMs. The use of nanomaterial content above $45 \mathrm{wt} \%$ resulted in 
cracked and deformed nanocomposite CEMs. There was no agglomeration observed in either the SGO/PVDF_45 or SrGO/PVDF_45 CEMs.

511 Both nanocomposite CEMs displayed lower linear swelling ratios, which are good for

512 membrane stability. This was due to the presence of the nanomaterials in both SGO/PVDF_45

513 and SrGO/PVDF_45 which acted as pore fillers and increases the stiffness of the

514 nanocomposite membrane. When comparing the effects of SGO versus SrGO additives, the

515 IEC and permselectivity of the SGO/PVDF_45 CEMs were slightly higher than values for the

516 SrGO/PVDF_45 CEM. It was found that the SrGO nanosheets increased the area resistance of

517 the SrGO/PVDF_45 CEM nanocomposite CEM. However, the SrGO/PVDF_45 CEM

518 demonstrated a higher current efficiency, which could be attributable to the improved

519 electronic conductivity of rGO.

520 It was found that both nanocomposite CEMs performed well in electrodialysis experiments to

521 achieve the substantial salt removal rate (SGO/PVDF_45 CEM (86 \%) and SrGO/PVDF_45

522 CEM (82\%)), although the energy consumption of the novel nanocomposite CEMs was higher

523 than the conventional polymeric CEM (PC S100). The above research results have successfully

524 shown the concept of fabricating nanocomposite cation exchange membranes (CEMs) for 525 electrodialysis applications by incorporating negatively charged graphene-based nanomaterials in a non-charged polymeric matrix, where the ion exchange capacity solely relies on the SGO or SrGO nanosheets. Additionally, these ion exchange group carriers of SGO or SrGO

528 nanosheets can also be incorporated into existing charged ion exchange polymeric matrix, to

529 enhance the performance of CEMs in electrodialysis in future research.

530 Conflict of interest

531 The authors declare no conflict of interest. 


\section{Acknowledgement}

This manuscript is part of a research collaboration between Masdar Institute-Khalifa University and University of Manchester (SMG2016-000001). The authors acknowledge the financial support of Khalifa University, Abu Dhabi, UAE, and the University of Manchester, UK. The authors would also like to thank Aikifa Raza and Hongxia Li for assisting with water contact angle measurements; and Andreas Dubbe, Patrick Altmeier, and Rebecca Jung from PCCell GmbH (Lebacher Str. 60, 66265 Heusweiler, Germany) for electrodialysis tests.

\section{References}

1. H. Strathmann, Electrodialysis, a mature technology with a multitude of new applications, Desalination, 2010, 264, 268-288.

2. Y. Tanaka, Ion-Exchange Membrane Electrodialysis for Saline Water Desalination and Its Application to Seawater Concentration, Ind. Eng. Chem. Res., 2011, 50, 7494-7503.

3. Y. Tanaka, Ion-exchange membrane electrodialysis program and its application to multi-stage continuous saline water desalination, Desalination, 2012, 301, 10-25.

4. A. Campione, L. Gurreri, M. Ciofalo, G. Micale, A. Tamburini and A. Cipollina, Electrodialysis for water desalination: A critical assessment of recent developments on process fundamentals, models and applications, Desalination, 2018, 434, 121-160.

5. H. Strathmann, "Ion-Exchange Membrane Processes in Water Treatment," in Sustainability Science and Engineering, eds. I. C. Escobar and A. I. Schäfer, Elsevier, 2010, vol. 2, pp. 141-199.

6. H. Strathmann, Introduction to membrane science and technology, Wiley-VCH Weinheim, Germany, 2013.

7. A. Moura Bernardes and M. A. S. Rodrigues, "Electrodialysis in Water Treatment," in Electrodialysis and Water Reuse: Novel Approaches, eds. A. Moura Bernardes, M. A. Siqueira Rodrigues and J. Zoppas Ferreira, Springer Berlin Heidelberg, Berlin, Heidelberg, 2014, DOI: 10.1007/978-3-642-40249-4_6, pp. 63-75.

8. H. Li and L. Zou, Ion-exchange membrane capacitive deionization: A new strategy for brackish water desalination, Desalination, 2011, 275, 62-66.

9. P. M. Biesheuvel and A. Van der Wal, Membrane capacitive deionization, J. Membr. Sci., 2010, 346, 256-262. 
10. S. Porada, R. Zhao, A. van der Wal, V. Presser and P. M. Biesheuvel, Review on the science and technology of water desalination by capacitive deionization, Prog. Mater Sci., 2013, 58, 1388-1442.

11. F. A. AlMarzooqi, A. A. Al Ghaferi, I. Saadat and N. Hilal, Application of Capacitive Deionisation in water desalination: A review, Desalination, 2014, 342, 3-15.

12. M. E. Suss, S. Porada, X. Sun, P. M. Biesheuvel, J. Yoon and V. Presser, Water desalination via capacitive deionization: what is it and what can we expect from it?, Energy Environ. Sci., 2015, 8, 2296-2319.

13. J. Ran, L. Wu, Y. He, Z. Yang, Y. Wang, C. Jiang, L. Ge, E. Bakangura and T. Xu, Ion exchange membranes: New developments and applications, J. Membr. Sci., 2017, 522, 267-291.

14. Khoiruddin, D. Ariono, Subagjo and I. G. Wenten, Surface modification of ionexchange membranes: Methods, characteristics, and performance, J. Appl. Polym. Sci., 2017, 134, 45540.

15. R. K. Nagarale, G. S. Gohil and V. K. Shahi, Recent developments on ion-exchange membranes and electro-membrane processes, Adv. Colloid Interface Sci., 2006, 119, 97-130.

16. A. Alabi, A. AlHajaj, L. Cseri, G. Szekely, P. Budd and L. Zou, Review of nanomaterials-assisted ion exchange membranes for electromembrane desalination, $n p j$ Clean Water, 2018, 1, 10.

17. S. Gahlot, P. P. Sharma, H. Gupta, V. Kulshrestha and P. K. Jha, Preparation of graphene oxide nano-composite ion-exchange membranes for desalination application, RSC Adv., 2014, 4, 24662-24670.

18. C. Yan, Y. W. Kanaththage, R. Short, C. T. Gibson and L. Zou, Graphene/Polyaniline nanocomposite as electrode material for membrane capacitive deionization, Desalination, 2014, 344, 274-279.

19. Y. He, C. Tong, L. Geng, L. Liu and C. Lü, Enhanced performance of the sulfonated polyimide proton exchange membranes by graphene oxide: Size effect of graphene oxide, J. Membr. Sci., 2014, 458, 36-46.

20. W.-H. Pan, S. J. Lue, C.-M. Chang and Y.-L. Liu, Alkali doped polyvinyl alcohol/multi-walled carbon nano-tube electrolyte for direct methanol alkaline fuel cell, J. Membr. Sci., 2011, 376, 225-232.

21. S. M. Hosseini, F. Jeddi, M. Nemati, S. S. Madaeni and A. R. Moghadassi, Electrodialysis heterogeneous anion exchange membrane modified by PANI/MWCNT composite nanoparticles: Preparation, characterization and ionic transport property in desalination, Desalination, 2014, 341, 107-114.

22. A. Alabi, L. Cseri, A. Al Hajaj, G. Szekely, P. Budd and L. Zou, Electrostaticallycoupled graphene oxide nanocomposite cation exchange membrane, J. Membr. Sci., 2020, 594, 117457.

23. B. G. Choi, J. Hong, Y. C. Park, D. H. Jung, W. H. Hong, P. T. Hammond and H. Park, Innovative polymer nanocomposite electrolytes: nanoscale manipulation of ion channels by functionalized graphenes, ACS Nano, 2011, 5, 5167-5174.

24. C.-Y. Tseng, Y.-S. Ye, M.-Y. Cheng, K.-Y. Kao, W.-C. Shen, J. Rick, J.-C. Chen and B.-J. Hwang, Sulfonated Polyimide Proton Exchange Membranes with Graphene Oxide 
show Improved Proton Conductivity, Methanol Crossover Impedance, and Mechanical Properties, Advanced Energy Materials, 2011, 1, 1220-1224.

610

611

612

613

614

615

616

617

618

619

620

621

622

623

624

625

626

627

628

629

630

631

632

633

634

635

636

637

638

639

640

641

642

643

644

645

646

647

648

649

650

651

25. S. Moulay, Dopa/Catechol-Tethered Polymers: Bioadhesives and Biomimetic Adhesive Materials, Polymer Reviews, 2014, 54, 436-513.

26. H. Lee, N. F. Scherer and P. B. Messersmith, Single-molecule mechanics of mussel adhesion, Proceedings of the National Academy of Sciences, 2006, 103, 12999.

27. A. Charlot, V. Sciannaméa, S. Lenoir, E. Faure, R. Jérôme, C. Jérôme, C. Van De Weerdt, J. Martial, C. Archambeau, N. Willet, A.-S. Duwez, C.-A. Fustin and C. Detrembleur, All-in-one strategy for the fabrication of antimicrobial biomimetic films on stainless steel, J. Mater. Chem., 2009, 19, 4117-4125.

28. S. Chen, B. Shen, F. Zhang, H. Hong and J. Pan, Mussel-Inspired Graphene Film with Enhanced Durability as a Macroscale Solid Lubricant, ACS Appl. Mater. Interfaces, 2019, 11, 31386-31392.

29. J. H. Ryu, P. B. Messersmith and H. Lee, Polydopamine Surface Chemistry: A Decade of Discovery, ACS Appl. Mater. Interfaces, 2018, 10, 7523-7540.

30. L. Yu, X. Liu, W. Yuan, L. J. Brown and D. Wang, Confined Flocculation of Ionic Pollutants by Poly(L-dopa)-Based Polyelectrolyte Complexes in Hydrogel Beads for Three-Dimensional, Quantitative, Efficient Water Decontamination, Langmuir, 2015, 31, 6351-6366.

31. S. Zheng, Q. Tu, J. J. Urban, S. Li and B. Mi, Swelling of Graphene Oxide Membranes in Aqueous Solution: Characterization of Interlayer Spacing and Insight into Water Transport Mechanisms, ACS Nano, 2017, 11, 6440-6450.

32. G.-d. Kang and Y.-m. Cao, Application and modification of poly(vinylidene fluoride) (PVDF) membranes - A review, J. Membr. Sci., 2014, 463, 145-165.

33. F. Liu, N. A. Hashim, Y. Liu, M. R. M. Abed and K. Li, Progress in the production and modification of PVDF membranes, J. Membr. Sci., 2011, 375, 1-27.

34. U. K. Sur, A. Saha, A. Datta, B. Ankamwar, F. Surti, S. D. Roy and D. Roy, Synthesis and characterization of stable aqueous dispersions of graphene, Bull. Mater. Sci., 2016, 39, 159-165.

35. Q. Wang, C. Aubry, Y. Chen, H. Song and L. Zou, Insights on Tuning the Nanostructure of rGO Laminate Membranes for Low Pressure Osmosis Process, ACS Appl. Mater. Interfaces, 2017, 9, 22509-22517.

36. J. Zhang, H. Yang, G. Shen, P. Cheng, J. Zhang and S. Guo, Reduction of graphene oxide via L-ascorbic acid, Chem. Commun., 2010, 46, 1112-1114.

37. M. J. Fernández-Merino, L. Guardia, J. I. Paredes, S. Villar-Rodil, P. Solís-Fernández, A. Martínez-Alonso and J. M. D. Tascón, Vitamin C Is an Ideal Substitute for Hydrazine in the Reduction of Graphene Oxide Suspensions, J. Phys. Chem. C, 2010, 114, 6426-6432.

38. J. Liu, R. Qu, P. Peng, W. Liu, D. Chen, H. Zhang and X. Liu, Covalently functionalized graphene oxide and quaternized polysulfone nanocomposite membranes for fuel cells, RSC Adv., 2016, 6, 71305-71310.

39. Y. Wei, X. Li, Q. Hu, C. Ni, B. Liu, M. Zhang, H. Zhang and W. Hu, Sulfonated nanocrystal cellulose/sulfophenylated poly(ether ether ketone ketone) composites for proton exchange membranes, $R S C A d v$., 2016, 6, 65072-65080. 
40. H. Strathmann, Ion-exchange membrane separation processes, Elsevier, Amsterdam, The Netherlands, First edn., 2004.

41. L. Cseri, J. Baugh, A. Alabi, A. AlHajaj, L. Zou, R. A. W. Dryfe, P. M. Budd and G. Szekely, Graphene oxide-polybenzimidazolium nanocomposite anion exchange membranes for electrodialysis, J. Mater. Chem. A, 2018, 6, 24728-24739.

42. N. Pismenskaia, P. Sistat, P. Huguet, V. Nikonenko and G. Pourcelly, Chronopotentiometry applied to the study of ion transfer through anion exchange membranes, J. Membr. Sci., 2004, 228, 65-76.

43. Y. Xu, K. Sheng, C. Li and G. Shi, Highly conductive chemically converted graphene prepared from mildly oxidized graphene oxide, J. Mater. Chem., 2011, 21, 7376-7380.

44. G. P. Kotchey, B. L. Allen, H. Vedala, N. Yanamala, A. A. Kapralov, Y. Y. Tyurina, J. Klein-Seetharaman, V. E. Kagan and A. Star, The Enzymatic Oxidation of Graphene Oxide, ACS Nano, 2011, 5, 2098-2108.

45. A. A. K. King, B. R. Davies, N. Noorbehesht, P. Newman, T. L. Church, A. T. Harris, J. M. Razal and A. I. Minett, A New Raman Metric for the Characterisation of Graphene oxide and its Derivatives, Scientific Reports, 2016, 6, 19491.

46. A. Radoń, P. Włodarczyk and D. Łukowiec, Structure, temperature and frequency dependent electrical conductivity of oxidized and reduced electrochemically exfoliated graphite, Physica E: Low-dimensional Systems and Nanostructures, 2018, 99, 82-90.

47. D. He, Z. Peng, W. Gong, Y. Luo, P. Zhao and L. Kong, Mechanism of a green graphene oxide reduction with reusable potassium carbonate, RSC Adv., 2015, 5, 11966-11972.

48. K. Cao, Z. Jiang, J. Zhao, C. Zhao, C. Gao, F. Pan, B. Wang, X. Cao and J. Yang, Enhanced water permeation through sodium alginate membranes by incorporating graphene oxides, J. Membr. Sci., 2014, 469, 272-283.

49. S. Ye, J. Feng and P. Wu, Highly elastic graphene oxide-epoxy composite aerogels via simple freeze-drying and subsequent routine curing, J. Mater. Chem. A, 2013, 1, 34953502.

50. S. Park, J. An, I. Jung, R. D. Piner, S. J. An, X. Li, A. Velamakanni and R. S. Ruoff, Colloidal Suspensions of Highly Reduced Graphene Oxide in a Wide Variety of Organic Solvents, Nano Lett., 2009, 9, 1593-1597.

51. S. M. Tan, A. Ambrosi, C. K. Chua and M. Pumera, Electron transfer properties of chemically reduced graphene materials with different oxygen contents, J. Mater. Chem. A, 2014, 2, 10668-10675.

52. D. Alemu, H.-Y. Wei, K.-C. Ho and C.-W. Chu, Highly conductive PEDOT:PSS electrode by simple film treatment with methanol for ITO-free polymer solar cells, Energy Environ. Sci., 2012, 5, 9662-9671.

53. M. J. González-Tejera, M. A. L. De Plaza, E. D. Sánchez La Blanca and I. HernándezFuentes, Electrochemical, FTIR and morphological study of polypyrrolePolystyrenesulphonate conducting films, Polym. Int., 1993, 31, 45-50.

54. L. Li, R. Ma, N. Iyi, Y. Ebina, K. Takada and T. Sasaki, Hollow nanoshell of layered double hydroxide, Chem. Commun., 2006, DOI: 10.1039/B605889B, 3125-3127.

55. G. Socrates, Infrared and Raman Characteristic Group Frequencies, John Wiley \& Sons, Ltd, 3rd edn., 2004. 
56. J. R. Potts, D. R. Dreyer, C. W. Bielawski and R. S. Ruoff, Graphene-based polymer nanocomposites, Polymer, 2011, 52, 5-25.

57. D. G. Papageorgiou, I. A. Kinloch and R. J. Young, Mechanical properties of graphene and graphene-based nanocomposites, Prog. Mater Sci., 2017, 90, 75-127.

58. S. Pei and H.-M. Cheng, The reduction of graphene oxide, Carbon, 2012, 50, 32103228.

59. V. Kumar, P. Kumar, A. Nandy and P. P. Kundu, A nanocomposite membrane composed of incorporated nano-alumina within sulfonated PVDF-co-HFP/Nafion blend as separating barrier in a single chambered microbial fuel cell, $R S C A d v$., 2016, 6, 23571-23580.

60. D. Ariono, Khoiruddin, Subagjo and I. G. Wenten, Heterogeneous structure and its effect on properties and electrochemical behavior of ion-exchange membrane, Mater. Res. Express, 2017, 4, 024006.

61. C. Gómez-Navarro, R. T. Weitz, A. M. Bittner, M. Scolari, A. Mews, M. Burghard and K. Kern, Electronic Transport Properties of Individual Chemically Reduced Graphene Oxide Sheets, Nano Lett., 2009, 9, 2206-2206.

62. H. Mao and P. G. Pickup, Electronically conductive anion exchange polymers based on polypyrrole: Preparation, characterization, electrostatic binding of ferrocyanide and electrocatalysis of ascorbic acid oxidation, J. Electroanal. Chem. Interfacial Electrochem., 1989, 265, 127-142.

63. I.-H. Loh, R. A. Moody and J. C. Huang, Electrically conductive membranes: Synthesis and applications, J. Membr. Sci., 1990, 50, 31-49. 